\title{
A Review of External Pressure Testing Techniques for Shells including a Novel Volume-Control Method
}

\author{
J.R. MacKay • F. van Keulen
}

Received: 20 March 2009 / Accepted: 26 June 2009 /Published online: 21 July 2009

(C) Defence R\&D Canada and the Netherlands Ministry of Defence 2009

\begin{abstract}
A review of conventional testing methods for applying external hydrostatic pressure to buckling-critical shells is presented. A new "volume-control" pressure testing method, aimed at preventing catastrophic specimen failures and improving control of specimen deformation near the critical load, is also introduced. The implementation of conventional and volume-control systems in an experimental program involving the destructive pressure testing of ring-stiffened cylinders is described. The volume control method was found to improve control of the specimen deformations, especially near the critical load, and catastrophic failures observed while using a conventional setup were avoided. The quasi-static tracking of postcollapse load-deformation relationships for snap-through buckling behaviour was possible while using a volumecontrol system, but precise control of dynamic shell deformations during buckling was not achieved for specimens failing with large buckling lobes. Expressions for estimating the available control over specimen deformations for pressure testing systems are presented.
\end{abstract}

Keywords External pressure - Hydrostatic pressure .

Shell $\cdot$ Buckling $\cdot$ Collapse $\cdot$ Experiment

\footnotetext{
J.R. MacKay $(\bowtie)$

Defence R\&D Canada-Atlantic,

9 Grove Street,

Dartmouth, NS B2Y 3Z7, Canada

e-mail: John.MacKay@drdc-rddc.gc.ca

J.R. MacKay $\cdot$ F. van Keulen

Maritime and Materials Engineering,

Delft University of Technology,

Mekelweg 2,

2628 CD Delft, The Netherlands
}

\section{Introduction}

Curved, thin-walled structures, which are under some manner of compressive loading, typically fail through instability in the form of elastic or inelastic buckling. These are the so-called "buckling-critical shells." This paper is concerned with shells loaded under hydrostatic external pressure. This class of structures includes pressure hulls of naval submarines, commercial and research submersibles, and autonomous underwater vehicles, as well as certain civil engineering and aerospace structures and those used in the offshore oil and gas industry. Hydrostatically loaded shells are typically designed using empirically-derived curves, which invoke a knock-down factor approach on the classical elastic buckling load (e.g. Refs. [1-3]). A significant research effort has been devoted to experimentally determining buckling pressures in order to study the mechanics involved in buckling, validate analytical theory and support the empirical design methodology.

Conventional methods for applying hydrostatic pressure to shell structure prototypes or experimental specimens are reviewed in this paper. These procedures have been widely and successfully used to determine shell strength; however, under certain conditions they exhibit some significant drawbacks, especially a tendency to allow the specimen to be catastrophically deformed and ruptured during the buckling event. Catastrophic failures are undesirable because they make it difficult or impossible to: 1) identify the mode and location of initial failure in order to identify weak structural features, 2) compare the initial buckling mode with analytical or numerical predictions, and 3) study the structural behaviour during and after the buckling event.

The paper begins with an explanation of load-, displacement- and generalized displacement-control, which are key concepts for the discussion of hydrostatic pressure 
testing to follow. Conventional pressure testing apparatus are then reviewed, followed by a description of the "volume-control" method, which was developed to address the deficiencies of conventional pressure testing methods. Simple expressions are presented for estimating the degree of control over the specimen deformation that can be expected for various pressure testing systems. The relative merits of conventional and volume-control systems are shown by examining the results of an experimental program, wherein both types of systems were used to test ring-stiffened cylinders. The paper concludes with recommendations for choosing an appropriate pressure testing system for a particular problem.

\section{Load-Versus Displacement-Control}

Structural strength testing and analysis can be divided into two broad categories when considering the application of the load: 1) "load-control" and 2) "displacement-control". Equilibrium path-following schemes used in nonlinear finite element analysis (FEA) are the computational counterparts to experimental methods for the application of load. As such, the difference between load and displacement-control can be demonstrated to a large extent by examining a popular benchmark problem for nonlinear FEA of shells: a hinged cylindrical panel under a central load (Fig. 1). This problem has been widely studied [4] because, depending on the particular geometry and material, these panels exhibit either or both types of dynamic "snapping": snap-through and snap-back, associated with limit points in the load and displacement, respectively. The

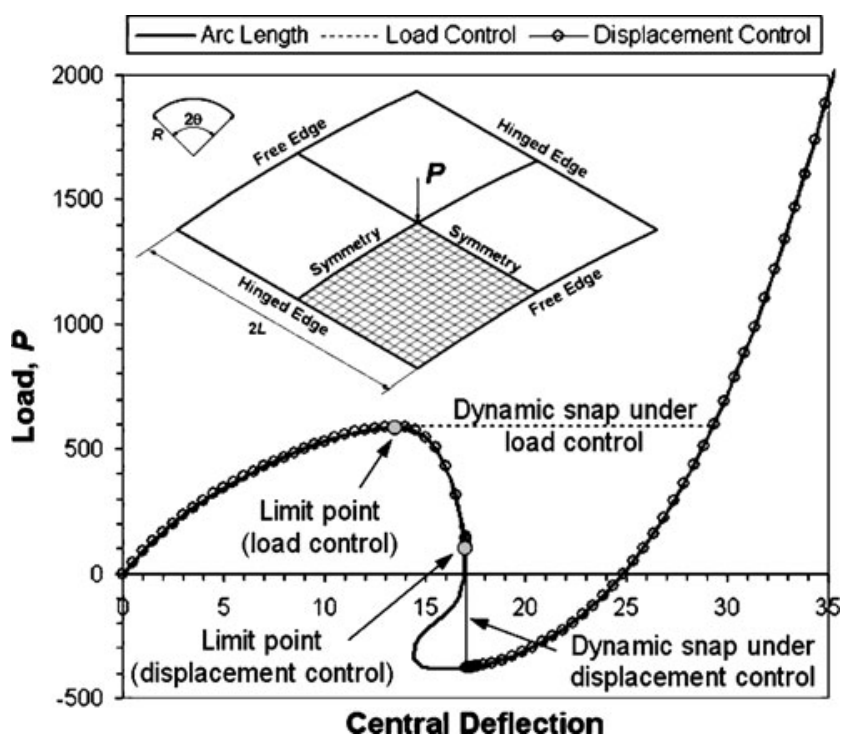

Fig. 1 Benchmark load-displacement curve for the hinged cylindrical panel described by the parameters in Table 1, and under a central load thick line in Fig. 1 represents the theoretical static equilibrium path for the panel defined by the parameters listed in Table 1 [4].

\section{Load-Control}

Load-control refers to the monotonic application of a load to a structure. In nonlinear FEA, the load is applied incrementally and an iterative scheme is employed to achieve equilibrium, i.e. a balance of external loads and internal stresses [5]. When a local maximum in the loaddisplacement relationship (e.g. the load limit point in Fig. 1) is reached, an experimental load-control system or FEA does not reduce the applied load to follow the true, though unstable, equilibrium path; instead, equilibrium is maintained by "jumping" to an adjacent configuration that is in equilibrium, is stable and is at the same or greater load level. This is called dynamic snapping.

There is no guarantee that a numerical model will find the stable equilibrium configuration, and in an experimental setting, the snapping may trigger a dynamic process that can potentially lead to an alternative equilibrium path or complete failure. Furthermore, dynamic snapping is only possible if the peak is a local maximum as in Fig. 1. When a global maximum is reached, the system has no other equilibrium configuration to jump to at that load level. Complete failure occurs soon thereafter in an experiment, while the numerical model will fail to find a solution.

\section{Displacement-Control}

Displacement-control refers to a system whereby displacements compatible with the load of interest, and associated with a reaction force (or forces), are applied monotonically [5]. Under displacement-control, the central deflection of the panel shown in Fig. 1 would be increased (e.g. using a hydraulic actuator in an experiment or an incremental-iterative procedure in nonlinear FEA), resulting in a corresponding reaction force. With reference to Fig. 1, when the first limit point in the load is reached, the displacement continues to be incremented with a corresponding drop in the reaction force. Dynamic snapping is postponed until the

Table 1 Geometry and material properties of hinged cylindrical panel

\begin{tabular}{ll}
\hline Radius, $R$ & 2540 \\
Length, $L$ & 254 \\
Sweep angle, $\theta$ & 0.1 radians \\
Thickness, $h$ & 6.35 \\
Young's modulus, $E$ & 3102.75 \\
Poisson's ratio, $v$ & 0.3 \\
\hline
\end{tabular}


limit point in the displacement is reached further along the equilibrium path.

\section{Generalized Displacement-Control}

The continuous equilibrium path shown in Fig. 1 was estimated using a spherical arc-length method. Arc-length methods, e.g. Refs. [6] and [7], are a form of generalized displacement-control, whereby the load factor is related to the generalized displacements via a constraint equation that requires convergence to occur within a specified loaddisplacement "arc". The so-called "spherical" arc-length method operates in both the load and displacement domain, while the "cylindrical" arc-length procedure prescribes only the generalized displacements. Both methods have been shown capable of quasi-statically traversing snap-through and snap-back behaviour [8]. Generalized displacementcontrol is commonly used in numerical analyses, but it is more difficult to implement experimentally since more than one displacement parameter must be controlled, not to mention simultaneous control of the load.

\section{External Pressure Testing Techniques}

Hydrostatic pressure tests are typically performed on ringstiffened cylinders, unstiffened tubes, hemi-spherical domes and other shells. For cylindrical structures, the hydrostatic design load differs from radial (lateral) pressure, which does not include the axial load. External pressures are sometimes generated by creating a partial vacuum within the specimen (e.g. Refs. [9-14]); however, this method is only useful for shells that buckle at pressures less than atmospheric pressure. This paper is concerned with hydrostatic pressure testing of shells loaded to pressures greater than atmospheric. A comprehensive historical and technical review of pressure testing of shells, and buckling experiments and testing theory in general, is given in Refs. [15] and [16].

\section{Mechanics of External Pressure Testing}

The main component of a typical pressure testing apparatus (Fig. 2) is the pressure chamber: a cylindrical, typically steel, vessel designed to withstand internal pressure. The pressure chamber is filled with the testing medium (e.g. water or oil) and sealed at either end once the experimental specimen has been placed inside. Pressure is increased by pumping additional testing fluid into the chamber, and monitored using a manometer or electronic pressure transducer.

Equilibrium of the system during pressurization involves compression of the testing fluid, expansion of the chamber, and deformation of the experimental specimen. The magnitude of load transferred to the specimen is therefore a function of the volume of testing fluid that is forced into the chamber by the pump, the stiffness of the pressure chamber and specimen, and the compressibility of the testing fluid. Even though most pressure testing systems are controlled by monitoring the applied pressure and adjusting the pumping rate, loading is actually achieved by applying a volume-change to the specimen via the testing apparatus, i.e. the testing fluid. As such, this system is a form of generalized displacement-control.

The compressibility of a fluid is defined by its bulk modulus, $B$, and initial volume, $V_{0}$. The quotient of these values can be considered an equivalent stiffness, $k^{*}$, when relating the pressure applied to a fluid, $\delta P$, to the corresponding incremental volume change, $\delta V[17]$ :

$\delta P=\frac{B}{V_{0}} \delta V=k^{*} \delta V$

The main difference between a conventional pressure testing system and a typical displacement-control test apparatus is the relatively greater compliance of the pressure testing fluid compared to traditional testing frames. This is due to the high compressibility of fluids compared to solids, as shown by the relatively low values of bulk modulus for fluids (e.g. the bulk moduli of water and steel are approximately $1.6 \mathrm{GPa}$ and $170 \mathrm{GPa}$, respectively). The discrepancy is compounded in pressure chambers having a large ratio of testing fluid to specimen volume, since this further reduces the stiffness of the pressure testing system compared to the specimen. This results in a relatively large amount of strain energy being built up in the testing fluid during pressurization. Traditional testing frames can improve control of the load and displacement by increasing the frame stiffness, i.e. adding material. Conversely, in a pressure testing system this can be achieved by taking away test rig material, i.e. reducing the volume of testing fluid.

In conventional pressure testing, the prescribed deformation must be transferred through the elastic and highly compressible fluid component, rather than directly controlling the deformation of the specimen. This is a problem for pressure testing of buckling-critical shells, since buckling involves a rapid change in the manner of load resistance, from largely membrane stresses to a combination of membrane and bending stresses, and is often accompanied by a substantial loss of overall stiffness [18]. This system may be treated as quasi-static up to the occurrence of buckling, at which point the system behaves dynamically. The large and rapid deformations associated with buckling trigger the release of strain energy stored in the compressed testing fluid, resulting in undesirable catastrophic failure if some method of reducing, slowing down or absorbing the released energy is not present [19]. Some researchers have 
Fig. 2 Conventional open-ended (a) and closed-ended (b) pressure testing apparatus

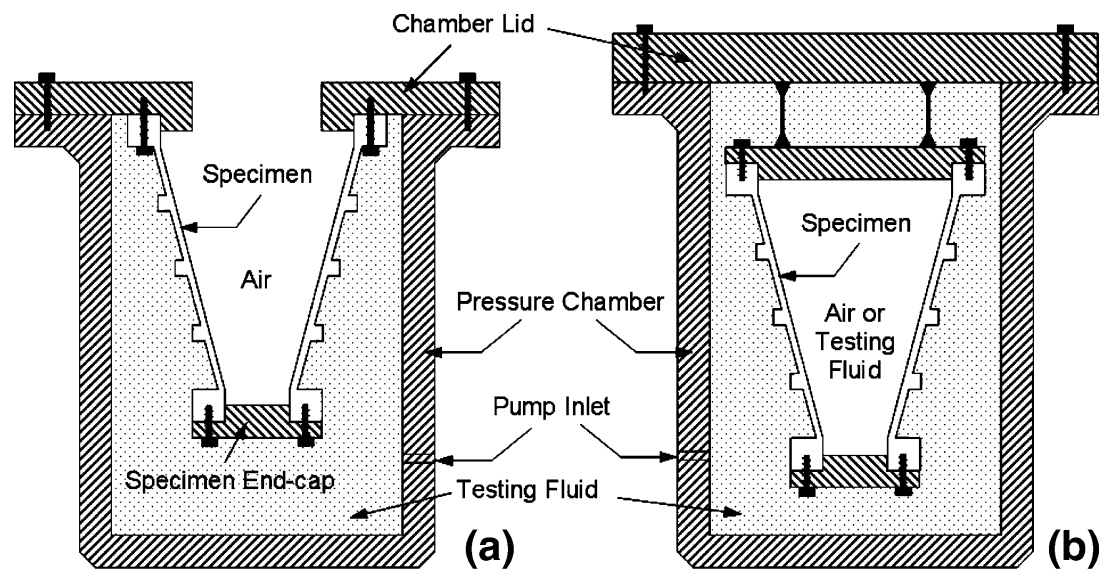

been able to reduce the damage at collapse by minimizing the volume of testing fluid, either by selectively proportioning their specimens and/or pressure chamber [23], or adding solid filler material to the test chamber [38]. However, these options are not always practical, e.g. when using an existing pressure chamber, or when filler blocks would interfere with the instrumentation.

Since conventional pressure testing systems are a form of generalized displacement-control, they are capable, in principle, of surpassing limit points in the load, although this does not rule out the possibility of snapping at limit points in the generalized displacements. In practice, the catastrophic nature of shell buckling events in combination with the associated release of energy stored in the testing fluid, means that the equilibrium path is not neatly traced beyond limit points when using traditional pressure testing methods.

\section{Conventional External Pressure Testing Methods}

Pressure testing apparatus are constructed in either of two typical arrangements: 1) "open-ended" chambers, e.g. Refs. [20-36], and 2) "closed-ended" chambers, e.g. Refs. [3756]. Figure 2(a) shows an open-ended pressure chamber, whereby the end-closure is designed to be directly attached to the specimen. The other end of the specimen must be sealed with an end-cap when testing a cylinder or truncated cone. Figure 2(b) shows a closed-ended arrangement, whereby both ends of the specimen are sealed with endcaps and the entire assembly is placed in the pressure chamber, which has a solid end-closure. Sealing of the endcaps and end-closures using o-rings or sealing compounds is normally required to achieve pressurization.

Open-ended pressure chambers allow access to the specimen during testing for observation (e.g. video recording) and instrumentation (e.g. strain gauges and displacement sensors); however, the specimens are necessarily "air-backed" in this system, so that it is difficult to control or absorb the energy released at collapse to check catastrophic failure.
Closed-ended test setups can mitigate these effects by filling, or partially filling, the specimen with the testing fluid before pressurization, e.g. Refs. [50-56]. This helps to dampen the post-collapse motions. The compression of a fully fluidbacked specimen results in an internal pressure load on the specimen, which works against the applied external pressure. The net or differential pressure is taken as the chamber pressure less the internal specimen pressure. As with conventional air-backed arrangements, the deformation is applied to the specimen indirectly via the chamber testing fluid.

Some researchers have used an arrangement that involves venting the inside of a fluid-filled specimen to the exterior of the pressure chamber, e.g. Refs. [50-53]. This type of setup, shown in Fig. 3(a), ensures that there is no back pressure in the specimen, at least during the quasistatic pre-buckling stage, and so it behaves like an airbacked system up to collapse while also dampening the specimen motions during the collapse event. Even so, as with the other conventional systems, direct control of the specimen deformation is not possible. A secondary advantage of this system is that the volume of fluid expelled from the specimen during testing (i.e. the volume change of the specimen) can be monitored and used to roughly estimate the load-deformation behaviour and identify the failure pressure [51].

Kinra [56] performed shell buckling tests using a closedended system and fluid-filled specimen with an outlet. The setup was the same as that shown in Fig. 3(a), except that a valve controlled the flow of testing fluid at the outlet. Testing proceeded by closing the valve and applying pressure to the system. This pre-pressurizing stage is analogous to a fully fluid-backed closed-ended system, as discussed above, i.e. there is a net load on the specimen. After pre-pressurizing the system to the desired level, the valve was opened, letting the pressurized fluid escape from the specimen. This simultaneously reduced the chamber pressure and increased the load on the specimen. The valve was then closed, and the procedure was repeated with 
Fig. 3 Modified (a) and volume-control (b) closed-ended pressure testing apparatus

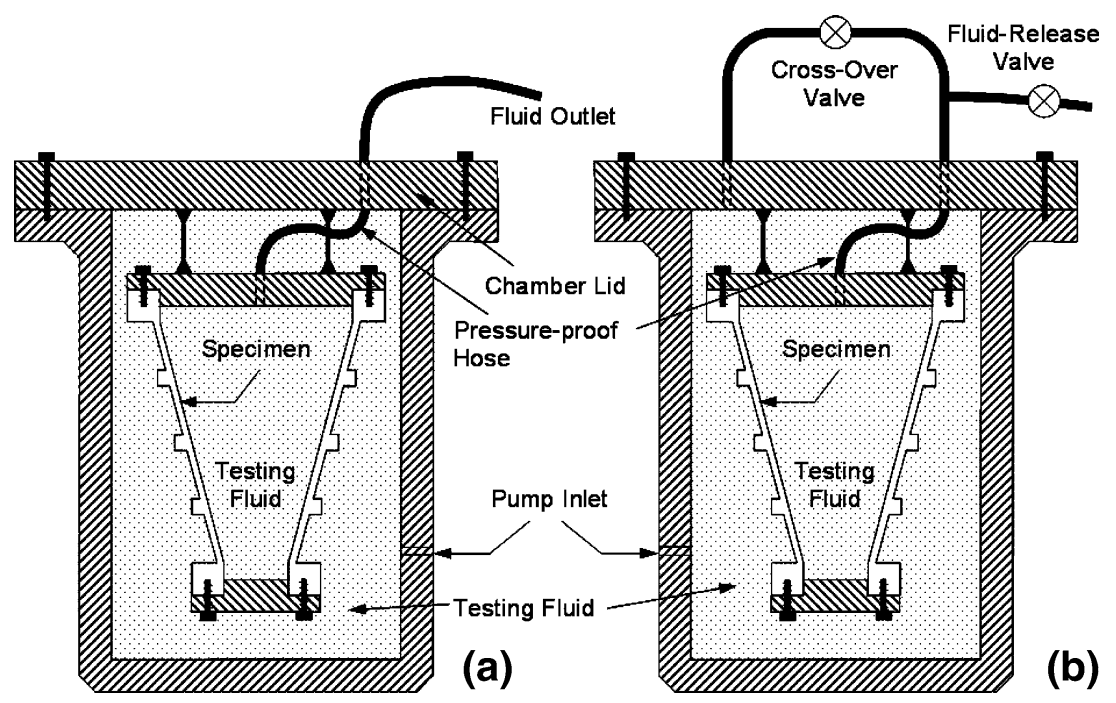

increasing levels of system pre-pressure until the specimen failed while the specimen fluid was being bled.

The system used by Kinra helped control the pre- and post-buckling motions, but had some drawbacks. Firstly, there was a risk of the specimen collapsing during prepressurization since it experienced a net load during this stage. Only the chamber pressure was monitored during testing, so the net load on the specimen would not have been known if it failed during pre-pressurization. Furthermore, the benefit of this system over other arrangements was the greater control of specimen deformation that was achieved by loading the specimen via the internal fluid; this advantage would be negated if the specimen failed during pre-pressurization. To ensure that the specimen did not fail at this stage, the final collapse load was approached incrementally. Finally, since only the chamber pressure was monitored, the collapse pressure could only be measured as bounded by the final two pressure increments in the chamber.

A substantially different method of applying hydrostatic pressure involves the application of radial pressure to the shell wall via a pressure chamber, in combination with some method of independently applying the axial load, e.g. using hydraulic actuators (Refs. [57-64]) or a second pressure chamber for the axial load (Refs. [65] and [66]). Figure 4 shows an example of this type of system that uses two pressure chambers and two pumps to control the radial and axial load independently. This setup is typically used for the testing of offshore structures, which may be required to resist axial loads in excess of those due to hydrostatic pressure. This type of system is more flexible than conventional pressure testing methods since the axial load is not a fixed function of the radial load; however, it is more difficult to implement since the two loads must be controlled simultaneously.
A Volume-Control External Pressure Testing Method

The main drawback of conventional pressure testing methods is that the deformation is applied to the specimen through a relatively compliant fluid medium that is uniformly loaded; that is, the stiffness of the testing system can only be increased by decreasing the volume of testing fluid, which, as mentioned earlier, is not always practical. The release of energy stored in the compressed testing fluid results in catastrophic buckling failures for air-backed specimens. For fluid-backed specimens, the post-buckling motions can be dampened, but the specimen deformation is still controlled indirectly by regulating the pressure in the chamber fluid via the pumping rate.

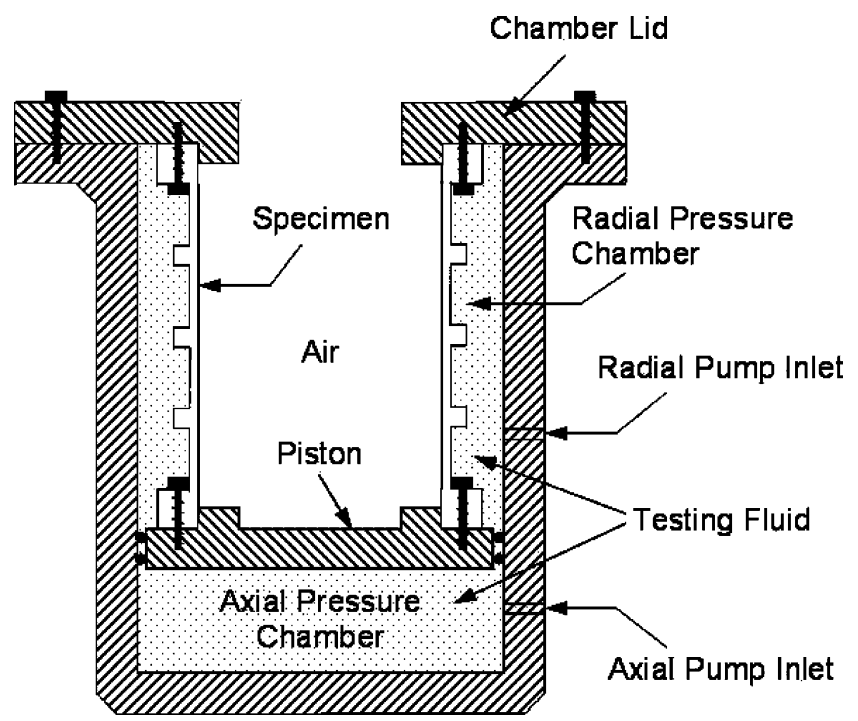

Fig. 4 Pressure testing apparatus with variable axial loading capability 
A pressure testing setup whereby the specimen deformation is managed more directly would allow the response of the specimen in the collapse and post-collapse regions to be better controlled and therefore studied more effectively. This paper presents such a system, referred to hereafter as the "volume-control" pressure testing technique. The goal of this system is to control the bulk specimen deformation, i.e. the generalized displacements, by controlling the volume of the specimen. Such a system was used by Kinra [56], but it had some significant drawbacks that were related to the specimen being loaded during the prepressurization stage. In the volume-control system advocated in this paper, the deficiencies of Kinra's method are addressed by uniformly loading the inside and outside of the specimen during pre-pressurization, i.e. no net load is applied to the specimen during pre-pressurization. The specimen is then loaded by decreasing the internal pressure while maintaining a more-or-less constant external load. The internal pressure and volume are controlled by carefully releasing the pre-pressurized testing fluid from inside the specimen.

A volume-control system is shown in Fig. 3(b). The specimen is first filled with the testing fluid and placed in the pressure chamber, which is also filled with the testing fluid. A pressure proof hose or pipe connects the inside of the specimen to the outside of the pressure chamber via a hole in the lid. High pressure hose is used to complete the loop connecting the inside of the specimen to the main pressure chamber via a second hole in the lid. Two valves are located in the pressure loop: the "fluid-release valve" located at a branch point in the loop, and the "cross-over valve", which can break the loop, isolating the inside of the specimen from the main chamber.

Testing proceeds by first pre-pressurizing the system. This is carried out by opening the cross-over valve and closing the fluid-release valve, and increasing the system pressure using a pump. Since the pressure loop is open during this stage, the system pressure increases with a net pressure of zero on the specimen. Once the system is prepressurized to the desired load, the pump can be turned off for the duration of the test.

External pressure is applied to the specimen by closing the cross-over valve and opening the fluid-release valve, allowing the pressurized fluid to escape from the specimen. This allows the specimen to deform and the fluid inside the specimen to expand, resulting in a decrease of internal specimen pressure and thus an increase in the net external pressure load on the specimen. Pressure in the main chamber and the specimen are monitored throughout loading; the net load on the specimen at any time is equal to the chamber or tank pressure less the specimen's internal pressure.

Of course, the amount of pre-pressure must be greater than the expected test or collapse load to allow for a loss in chamber pressure as the specimen contracts. The required additional pre-pressure depends on the volume and stiffness of both the chamber and the specimen. The load can be reversed at any point by closing the fluid-release valve and opening the cross-over valve, allowing the system to achieve equilibrium.

The rate of pressure loading is controlled by the amount of fluid released from the specimen (i.e. "volume-control"). The volume-control technique is therefore a form of generalized displacement-control whereby the controlled parameter is the volume of fluid removed from the specimen rather than the volume of fluid pumped into the chamber, as in conventional pressure testing methods. If the specimen volume is significantly less than the chamber volume, the specimen fluid will be significantly less compliant than the fluid in the chamber. This is analogous to using a stiffer testing frame in a displacement-control test, and should allow better control of specimen deflections than with conventional methods. Loading with the volume-control method proceeds by slowly releasing the pre-pressurized fluid from the system, which is an improvement over the conventional method of forcing extra fluid into the system using a pump.

\section{Control of Specimen Deformation Using Various Pressure Testing Methods}

For any given test rig for shell buckling experiments, it is desirable to estimate the amount of control over the specimen displacement that is available in order to compare systems and make informed choices when planning an experimental program. In this context, "control" is a measure of how completely the applied displacement of a test rig is passed on to the shell specimen. Ideally, the test rig will be infinitely stiff, so that the applied displacements are passed on to the specimen in a one-to-one manner. This is important because, even though the stiffness of the test rig does not influence the quasi-static pre-buckling path or the buckling load, the dynamic post-buckling behaviour of the specimen will be affected by the test rig stiffness [16]. The same applies to the specific case of externally pressurized shells, the relevant test rig in this case being the testing fluid. The post-buckling behaviour is influenced through the release of the built-up strain energy in the testing fluid, as mentioned earlier, so that the test rig, i.e. the fluid, should be as stiff as possible in order to minimize the accumulation of energy.

The degree of control of the generalized shell displacement for external pressure tests is estimated in this paper in two ways: 1) by determining the change in volume of the specimen, $\Delta u_{2}$, relative to the applied volume change in the testing system, $\Delta u_{1}$, for the pre-buckling path (also applicable to limit-point buckling that does not involve a 
sudden loss of specimen load-carrying capability); and 2) by determining the change in specimen volume, $\Delta u_{2}$, as a result of the abrupt loss of load-carrying capability experienced during collapse, while $\Delta u_{1}$ is fixed at zero. $\Delta u_{1}$ is the amount of fluid pumped into the pressure chamber for conventional systems and the volume of fluid released from the specimen for volume-control systems.

Perfect specimen control in the pre-buckling range is indicated by a $\left(\Delta u_{2} / \Delta u_{1}\right)$ ratio of unity; that is, one unit of volume change in the testing apparatus results in one unit of specimen deformation. However, $\left(\Delta u_{2} / \Delta u_{1}\right)<1$ is normal for the practical setting since the testing fluid must have a finite compressibility and the specimen a finite stiffness (at least before buckling occurs). The degree of control of a particular system can be estimated by how close this value approaches unity, which is analogous to an infinitely stiff testing rig.

\section{Spring diagrams for pressure testing systems}

The $\left(\Delta u_{2} / \Delta u_{1}\right)$ ratio, referred to hereafter as the "relative displacement", can be estimated by studying equilibrium and associated rate equations for equivalent spring diagrams representing pressure testing systems. Spring diagrams developed for conventional and volume-control systems are shown in Figs. 5 and 6, respectively. The stiffness of the springs representing the chamber fluid, specimen fluid and specimen are indicated by $k_{c}, k_{s f}$ and $k_{s}$, respectively. Figure 5(c), representing a conventional fluidfilled system with an outlet, includes a dashpot with damping constant, $c_{s f}$, to indicate the damping action of the specimen fluid.

In these diagrams, the specimen is represented as a coil, indicating a nonlinear spring. The internal force in the specimen spring, $F_{S}$, is a nonlinear function, $g$, of its elongation, $\Delta l_{s}=-u_{2}$. The specimen is not represented in the pre-pressurization stages for the volume-control arrangement, since the net load on it is zero. The stiffness of the pressure chamber itself, which is normally relatively large, is neglected. These diagrams and the following derivations refer to displacements and forces; however, these parameters are analogous to volumes (or generalized-displacement) and pressures in a pressure testing system.

\section{Development of the equilibrium equations}

For the pressure testing systems discussed here, equilibrium dictates that the force in the chamber fluid spring, $F_{c f}$, must be balanced by the force in the specimen spring, $F_{s}$, plus the force in the specimen fluid spring, $F_{s f}$, if applicable:

$F_{c f}=F_{s}+F_{s f}$ (a) Air-backed pressure testing

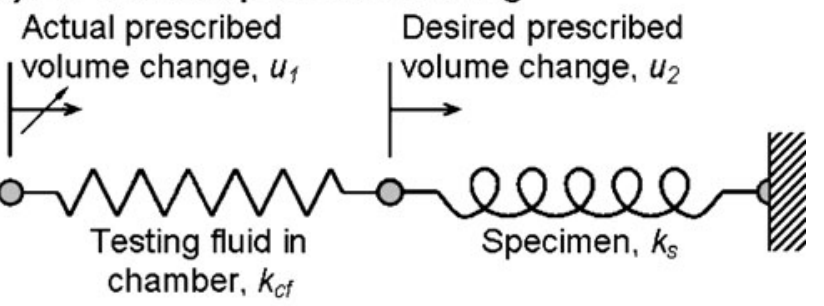

(b) Fluid-backed pressure testing

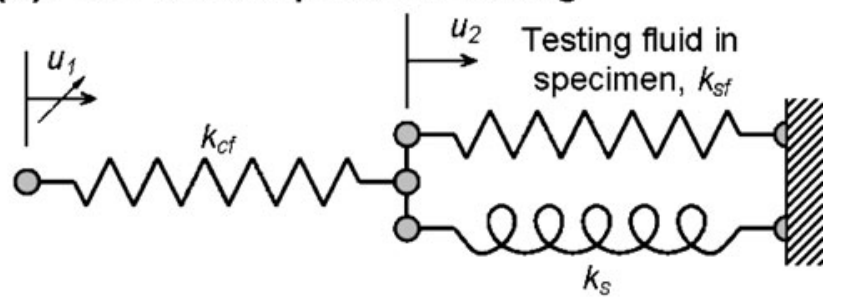

(c) Fluid-backed pressure testing with outlet

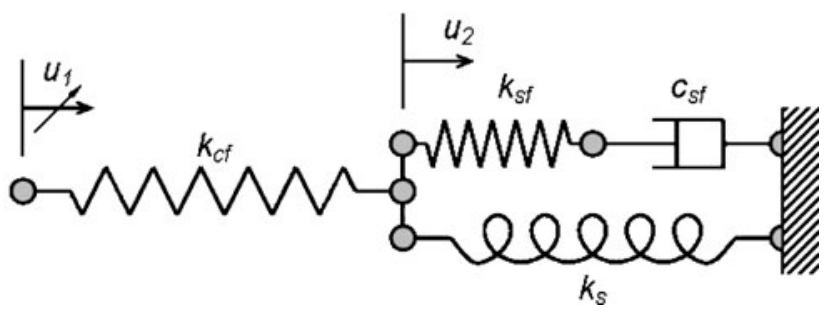

Fig. 5 Schematic spring diagrams of conventional pressure testing systems (a sloping arrow indicates the control variable)

The evaluation of each of the forces in equation (2) depends on the pressure testing system being studied. This is straightforward for conventional systems: the force in a spring is the product of its stiffness and net elongation, $\Delta l$. However, for a volume-control system, the total force in the

(a) Undeformed configuration

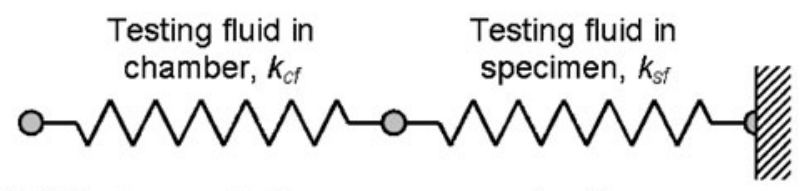

(b)During and after pre-pressurization

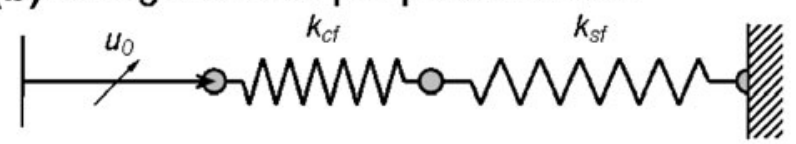

(c) Specimen loading

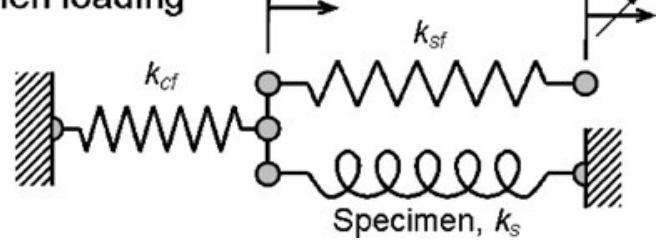

Fig. 6 Schematic spring diagram of a volume-controlling pressure testing system (a sloping arrow indicates the control variable) 
chamber fluid and specimen fluid springs is the force resulting from pre-pressurizing the system, $F_{0}$, plus the internal spring force as the specimen is loaded. The force expressions for the various pressure testing systems are summarized in Table 2.

\section{Pre-buckling relative displacement expressions}

An equilibrium expression for each pressure testing method is given by substituting the appropriate spring force expressions from Table 2 into equation (2). The sensitivity of the system to an incremental volume change can be studied by taking the derivative of each term in the equilibrium expression with respect to time, which results in a rate equation for each method. For example, the equilibrium equation for a conventional air-backed system is shown below:

$k_{c f}\left(u_{2}-u_{1}\right)=g\left[\Delta l_{s}\right]=g\left[-u_{2}\right]$

Taking the time derivatives of the displacement and force terms in equation (3) yields the following rate equation:

$k_{c f}\left(\dot{u}_{2}-\dot{u}_{1}\right)=\dot{g}\left[-u_{2}\right]=-\frac{d g}{d \Delta l_{s}} \dot{u}_{2}=-k_{s} \dot{u}_{2}$

In equation (4), the derivative of the specimen spring force, $g$, with respect to its elongation, $\Delta l_{s}$ is replaced by the tangent stiffness of the specimen, $k_{s}$. The resulting rate equation can be written in incremental notation in order to study the effects of small changes in the displacement:

$k_{c f}\left(\Delta u_{2}-\Delta u_{1}\right) \approx-k_{s} \Delta u_{2}$

Finally, by rearranging the terms in equation (5), the relationship between the relative displacement and the various spring stiffnesses can be expressed:

$\frac{\Delta u_{2}}{\Delta u_{1}} \approx \frac{k_{c f}}{k_{c f}+k_{s}}=\frac{1}{1+k_{s} / k_{c f}}$

Equation (6) can be used to estimate the relative displacement of the specimen for the pseudo-static prebuckling response using a conventional air-backed system. The relative displacement equations for other pressure testing systems are developed in a similar manner, with the expression for a conventional fluid-backed system given by the following equation:

$\frac{\Delta u_{2}}{\Delta u_{1}} \approx \frac{1}{1+\left(k_{s}+k_{s f}\right) / k_{c f}}$

The relative displacement equation for the volumecontrol system is shown below:

$\frac{\Delta u_{2}}{\Delta u_{1}} \approx \frac{1}{1+\left(k_{s}+k_{c f}\right) / k_{s f}}=\frac{k_{s f}}{k_{c f}}\left(\frac{1}{1+\left(k_{s}+k_{s f}\right) / k_{c f}}\right)$

The system used by Kinra [56] behaves like a conventional fluid-backed system (equation (7)) during prepressurization and like a volume-control system (equation (8)) during the loading stage.

The relative performance of the various systems in the pre-buckling range may be studied by examining the behaviour of the relative displacement equations. Figure 7 shows the relative displacement for each system as the ratio of specimen fluid to chamber fluid stiffness $\left(k_{s f} / k_{c f}\right)$ is varied, while fixing the ratio of specimen to chamber fluid stiffness $\left(k_{s} / k_{c f}\right)$ at finite values. Figure 7 , along with equations (6) and (7), indicates that specimen control for a conventional air-backed system will always be better than for a similar conventional fluid-backed system, since the chamber fluid in a fluid-backed system must work against both the specimen and specimen fluid stiffness. This suggests that the main advantage of a fluid-backed system (without an outlet) is the damping effect of the fluid during buckling. A fluid-backed system with an outlet behaves like an air-backed system for the pseudo-static pre-buckling region, and is thus governed by equation (6). So, it has the advantage of greater pre-buckling specimen control relative to a fluid-backed system without an outlet, and also provides damping to buckling motions.

Equations (7) and (8) indicate that the relative displacement of a volume-control system is given by the relative displacement of a similar conventional fluid-backed system, multiplied by the ratio of the stiffnesses of the fluid in the specimen and the chamber. If it is assumed that the same testing fluid is used in the specimen and the chamber, this implies that a conventional fluid-backed system will perform better in the pre-buckling stage if the volume of chamber fluid is less than the volume of fluid in the specimen. Conversely, if the internal volume of the shell
Table 2 Expressions for internal forces in components of pressure testing systems

\begin{tabular}{llll}
\hline Force & Conventional air-backed system & Conventional fluid-backed system & Volume-control system \\
\hline$F_{c f}$ & $k_{c f}\left(u_{2}-u_{1}\right)$ & $k_{c f}\left(u_{2}-u_{1}\right)$ & $F_{0}+k_{c f} u_{2}$ \\
$F_{s f}$ & $\mathrm{~N} / \mathrm{A}$ & $k_{s f}\left(-u_{2}\right)$ & $F_{0}+k_{s f}\left(u_{1}-u_{2}\right)$ \\
$F_{s}$ & $g\left[\Delta l_{s}\right]$ & $g\left[\Delta l_{s}\right]$ & $g\left[\Delta l_{s}\right]$ \\
\hline
\end{tabular}


Fig. 7 Relative displacement of pressure testing systems determined by varying the ratio of specimen fluid to chamber fluid stiffness while fixing other parameters

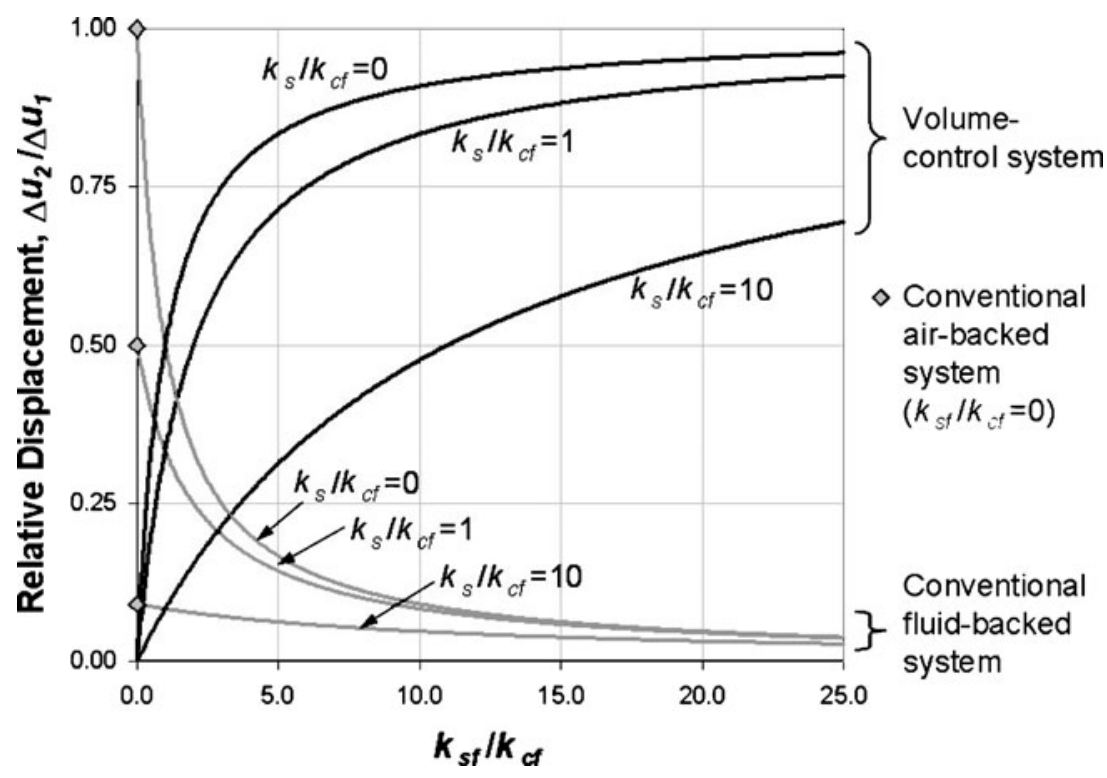

specimen is less than the volume of fluid in the pressure chamber, the volume-control method will show better performance. This is shown in Fig. 7 by the coincidence of the relative displacement of the volume-control and fluid-backed systems at $\left(k_{s f} / k_{c f}\right)=1$. This figure also shows that when the specimen stiffness is negligible compared to the fluid stiffnesses, a conventional air-backed system will have the greatest relative displacement.

A common feature of equations (6) through (8) is that control of specimen deformation is predicted to increase as the specimen stiffness, $k_{s}$, approaches zero, i.e. as the buckling load is approached. These expressions are based on assumptions of static behaviour and a continuous specimen force function, $g$. Real buckling is a dynamic event, typically involving a rapid loss of load-bearing capability. In practice, control of the specimen deformations may steadily improve as the buckling load is approached, but these equations are not valid during the buckling event itself. In the following sub-section, the response of a specimen to an abrupt change in loadbearing capacity will be examined for testing with the various systems.

\section{Incremental specimen displacement during buckling}

The relative displacement equations that have been presented are useful for determining the pseudo-static response of the system; however, the response of the system to large, abrupt changes in the load-carrying capability of the specimen during collapse can also be studied. This can be accomplished by returning to the rate equation (4) for a conventional airbacked system, and looking at what happens at the instance of collapse, i.e. by fixing the system displacement, $u_{1}$, and determining the incremental specimen displacement relative to a change in the internal specimen force function, $g$. The rate equation is given by:

$k_{c f}\left(\dot{u}_{2}-\dot{u}_{1}\right)=\dot{g}$

The incremental change in specimen displacement for a given change in specimen load-bearing capability is given by setting $\dot{u}_{1}$ in equation (9) equal to zero, and switching to incremental notation:

$\Delta u_{2} \approx \frac{\Delta g}{k_{c f}}$

A similar procedure yields the following expression, which applies to conventional fluid-backed as well as volume-control systems:

$\Delta u_{2} \approx \frac{\Delta g}{k_{c f}+k_{s f}}$

Equation (11) can also be applied to a conventional airbacked system by substituting a value of zero for $k_{s f}$. Since the incremental displacement of the specimen at collapse is inversely proportional to the sum of the stiffnesses of the various fluids in the system, any fluid-backed system will tend to arrest the buckling displacements better than an airbacked system. These incremental equations do not take dynamic effects, i.e. inertia and the damping effects of the internal specimen fluid, into account, which would further reduce the performance of an air-backed system compared to similar fluid-backed systems.

Figure 8 shows the incremental specimen displacement during buckling, normalized with respect to chamber fluid stiffness and incremental load, versus the ratio of specimen fluid to chamber fluid stiffnesses. This figure is based on 
Fig. 8 Incremental specimen displacement during buckling, normalized with respect to chamber fluid stiffness and incremental load, versus the ratio of specimen fluid to chamber fluid stiffnesses

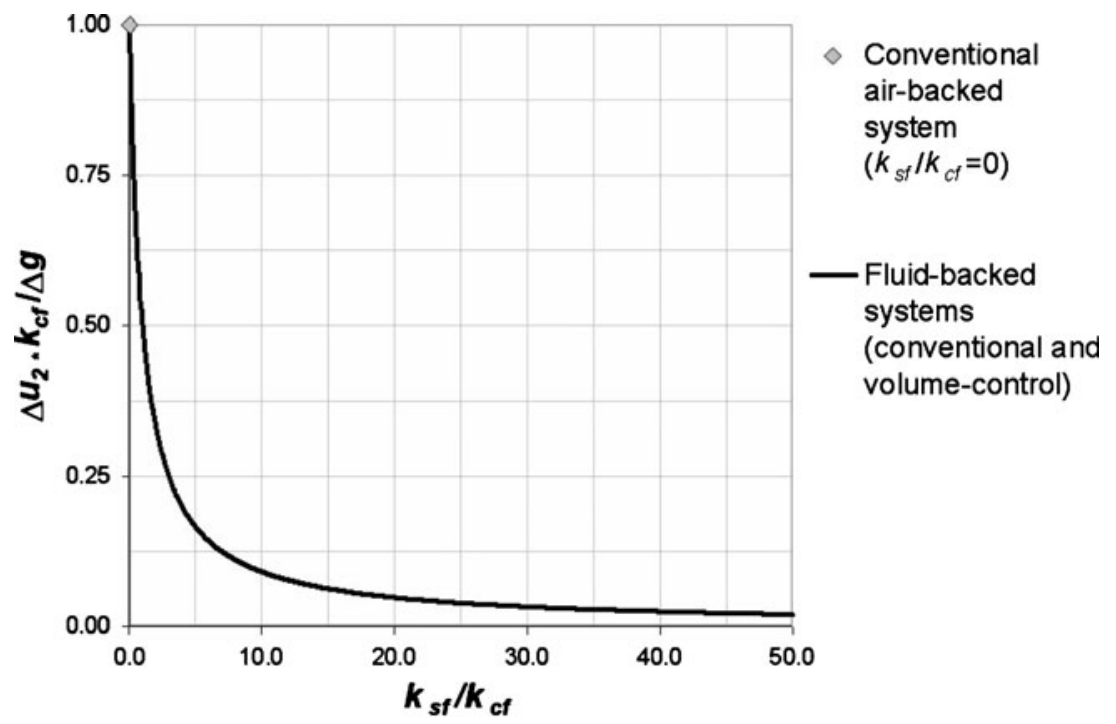

equation (11), and shows that the incremental specimen displacements during buckling are reduced as the specimen fluid stiffness is increased, for a given chamber fluid stiffness.

A review of the relative displacement expressions and incremental equations for buckling suggests that: 1) a conventional air-backed system will provide better specimen control than a similar fluid-backed system for the prebuckling region; 2) a conventional fluid-backed system provides greater resistance to the buckling displacements than a similar air-backed system; and 3) the volume-control method provides good control of both the pre-buckling and buckling displacements, and is especially advantageous for large values of $\left(k_{s f} / k_{c f}\right)$, i.e. for large pressure chambers in relation to specimen volume.

\section{Experimental Studies}

An experimental program was undertaken whereby stiffened shells were pressure tested to collapse using a conventional closed-ended air-backed method for some specimens [19] and the volume-control method for others [67]. These experiments allowed comparison of the volumecontrol method with a conventional technique, and provided validation (or invalidation) of several conjectured features of the former method; namely its ability to: a) apply external pressure to a shell specimen, b) prevent catastrophic buckling failures, c) preserve the initial collapse mode of the shell specimen, and d) allow control of the specimen deformation, especially near the critical load. The following sections present a brief overview of the test specimens, followed by the results of the testing program, especially with respect to validation of the various features of volume-control testing listed above.

\section{Test Specimens and Experimental Setup}

The pressure testing of three different types of experimental shell specimens, referred to hereafter as "short", "long" and "unstiffened", is examined. The short specimens (Fig. 9) were ring-stiffened cylinders, designed to fail inelastically in an "interframe" mode; that is, collapse of the shell plating between stiffeners, with a large number of circumferential buckling waves, $n \geq 5$ [68]. Long specimens (Fig. 10) were ring-stiffened cylinders that were designed to fail inelastically in an "overall" mode; that is, the combined collapse of rings and shell, with $n \leq 4$ [68]. This testing program was also designed to study the strengthreducing effect of material loss due to corrosion by machining away shell and stiffener material on selected specimens. As such, the long ring-stiffened cylinders have been artificially "corroded" by machining away material on the stiffener flange in a "dog-bone" pattern, as shown in the inset of Fig. 10(a).

The unstiffened specimen (Fig. 11) was an aluminium tube of uniform shell thickness, having roughly the same dimensions as the long ring-stiffened cylinder. The unstiffened specimen was designed to fail by elastic buckling with three or four buckling waves about the circumference, distributed in a half wave over the length.

All test specimens were machined from solid aluminium tubing. The overall sizes of the short, long and unstiffened specimens are shown in Figs. 9(a), 10(a) and 11(a), respectively. Detailed descriptions of the test specimens are given in Refs. [19] and [67]. Measurement of the fabricated specimens indicated that the maximum initial geometric imperfections were less than 0.1 times the mean shell thickness for all specimens discussed in this paper.

Two short and two long ring-stiffened cylinders have been tested, using both conventional and volume-control 
Fig. 9 Typical short cylinder specimens before (a) and after (b and $\mathbf{c}$ ) pressure testing

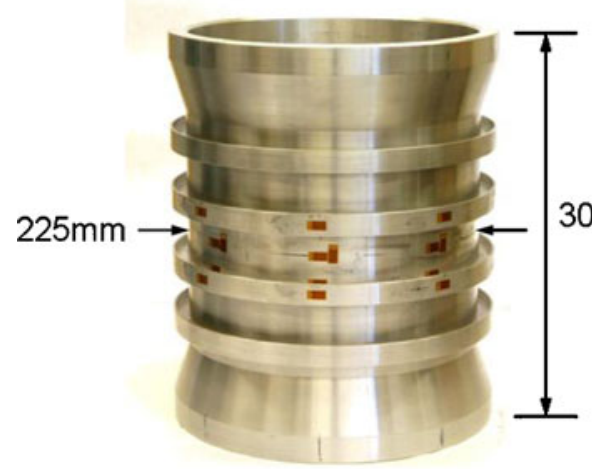

(a) Before pressure testing

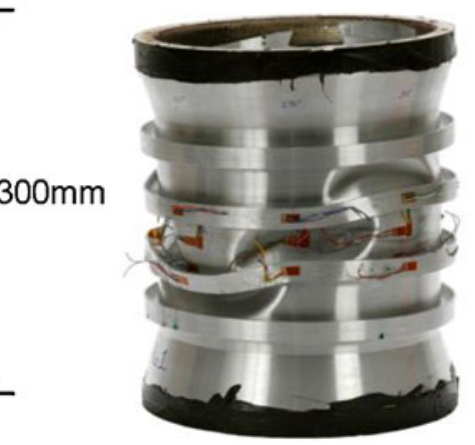

(c) After volume-control pressure testing

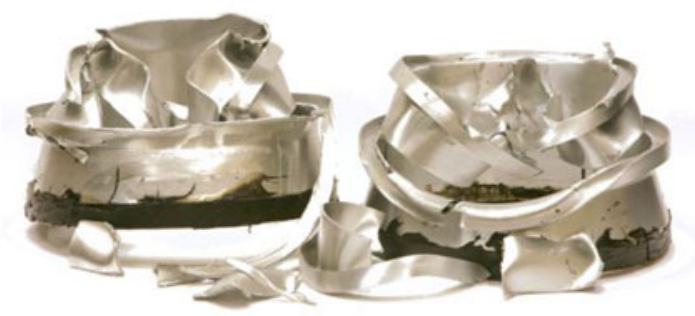

(b) After conventional pressure testing

methods for comparison. A single unstiffened cylinder was tested using the volume-control method. Before testing, whether conventional or volume-control, heavy steel endcaps were attached to either end of the specimen with bolts, and the end-cap joints were made watertight using an adhesive polymer sealant.

Strain gauges were attached to selected cylinders at critical locations in order to allow their full load-deformation history to be recorded. A typical specimen had strain gauges oriented in the circumferential direction on the central stiffener flanges, as well as longitudinally and circumferentially oriented gauges on the outside of the shell in the central bay. Strain gauges were distributed about the circumference in uniform $30^{\circ}$ or $45^{\circ}$ increments. Additional strain gauges were attached to the long cylinder in the region of simulated corrosion.

The volume-control pressure testing system used in these experiments was produced by outfitting an existing conventional pressure testing system, as shown in Fig. 2(b), with the necessary high pressure hoses, pipes and valves as
Fig. 10 Typical long cylinder specimens with simulated corrosion before (a) and after (b and c) pressure testing

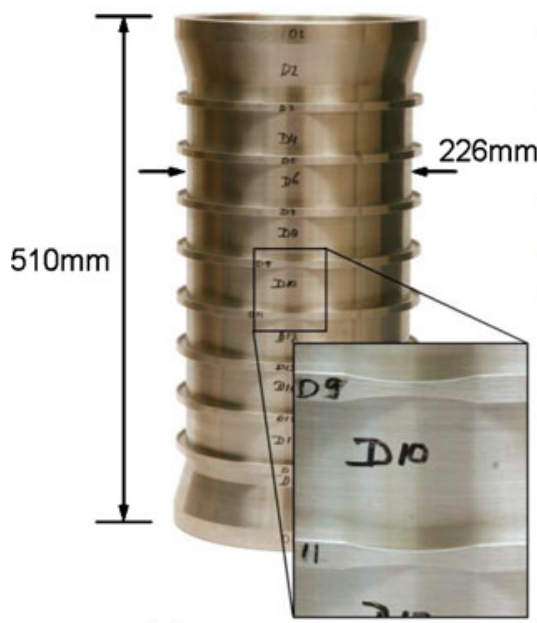

(a) Before pressure testing, with inset showing "dog-bone corrosion"

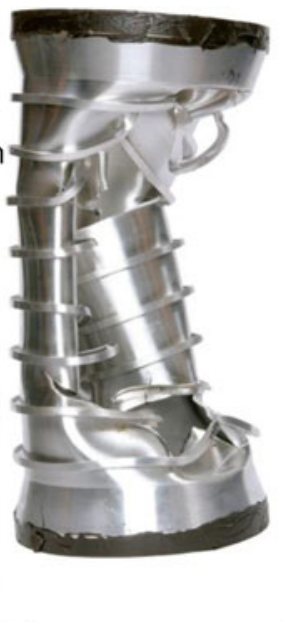

(b) After conventional pressure testing

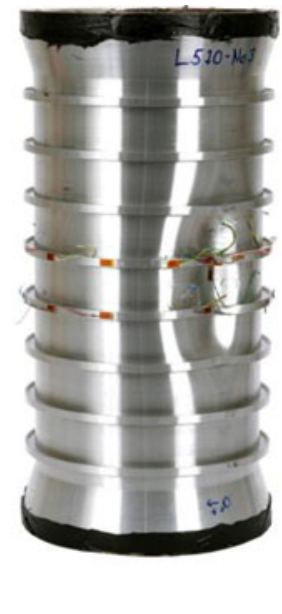

(c) After volume-control pressure testing 


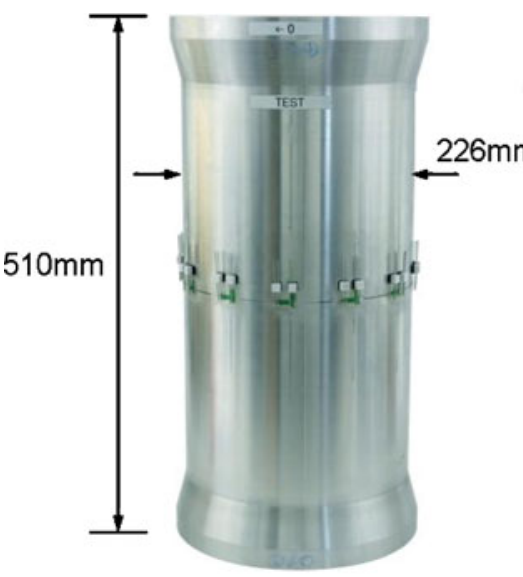

(a) Before pressure testing (b) After volume-control pressure testing

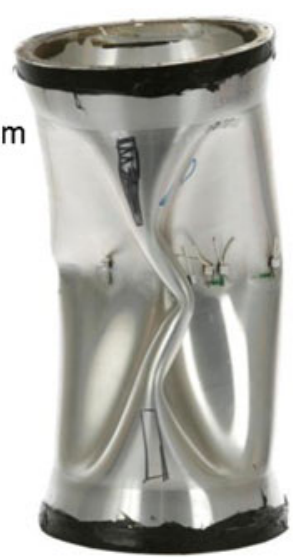

Fig. 11 Unstiffened specimen before (a) and after (b) pressure testing

shown in Fig. 3(b). The pressure chamber has an internal volume of approximately $1600 \mathrm{~L}$, while the short and long specimens displaced about $12 \mathrm{~L}$ and $20 \mathrm{~L}$ of testing fluid, respectively. Precise control of the fluid flow was achieved using needle valves. A non-conductive mineral oil was used as the testing fluid, rather than water. This prevented shorting of the electronic equipment without the requirement to seal strain gauges and lead wires against water infiltration.

\section{Capability to Generate External Pressure}

The full loading history, including system pre- and depressurization, was not recorded for the specimens discussed in this paper; however, Fig. 12 shows a typical loading history for the volume-control system used in these tests, recorded during the pressure testing of a similar ringstiffened cylinder. The markers on the time axis $\left(t_{0}, t_{1}\right.$, etc.) indicate milestones in the testing procedure. These milestones, as well as time intervals (e.g. $t_{2}-t_{3}$ ), will be referred to in the following discussion. Table 3 summarizes the status of the pump and valves during the various stages of testing.

The cross-over valve is open for system pre- and depressurization $\left(t_{0}-t_{1}\right.$ and $t_{5}-t_{6}$, respectively), which is indicated by the coincidence of the chamber and specimen pressures in Fig. 12. This valve is closed during specimen loading $\left(t_{2}-t_{4}\right)$, which is undertaken by releasing the testing fluid from inside the specimen via the fluid-release valve. The pre-collapse portion of the loading history $\left(t_{2}-t_{3}\right)$ shows a steadily decreasing loading rate. This results from setting the fluid-release valve once, at the onset of loading, after which the internal specimen pressure is continuously decreasing and, correspondingly, the flow rate of the fluid escaping from the specimen.

Collapse of the specimen is indicated by a sharp drop in net pressure at $t_{3}$, followed by a steadily dropping net pressure as the specimen is loaded into the post-collapse region $\left(t_{3}-t_{4}\right)$. The fluid-release valve is closed at $t_{4}$, preventing further deformation of the specimen, and the cross-over valve is opened allowing the system to reach equilibrium and thus unloading the specimen $\left(t_{4}-t_{5}\right)$.

The general capability of the volume-control system to apply external hydrostatic pressure to a shell specimen is indicated by the net pressure load shown in Fig. 12. The response of the strain gauges indicated that the experimental strain-pressure relationships were in good agreement with numerical predictions for these specimens [69].
Fig. 12 Complete load history for a typical volume-control pressure test

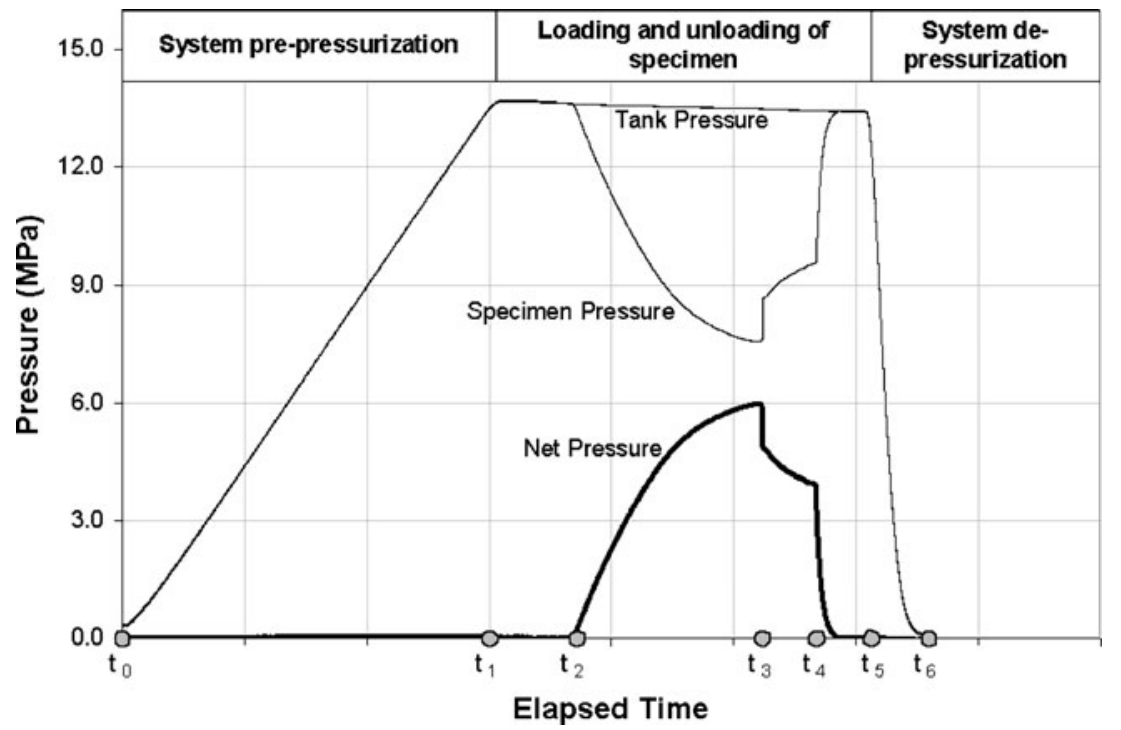


Table 3 Stages of a volumecontrol pressure test

\begin{tabular}{lllll}
\hline Time interval & Process & Pump & Cross-over valve & Fluid-release valve \\
\hline $\mathrm{t}_{0}-\mathrm{t}_{1}$ & System pre-pressurization & On & Open & Closed \\
$\mathrm{t}_{1}-\mathrm{t}_{2}$ & Checking equipment & Off & Open & Closed \\
$\mathrm{t}_{2}-\mathrm{t}_{3}$ & Loading (pre-collapse) & Off & Closed & Open \\
$\mathrm{t}_{3}-\mathrm{t}_{4}$ & Loading (post-collapse) & Off & Closed & Open \\
$\mathrm{t}_{4}-\mathrm{t}_{5}$ & Unloading & Off & Open & Closed \\
$\mathrm{t}_{5}-\mathrm{t}_{6}$ & System de-pressurization & Off & Open & Open \\
\hline
\end{tabular}

Prevention of Catastrophic Buckling Failure

Figures 9(b) and 10(b) show typical specimens after conventional air-backed pressure testing, which resulted in catastrophic failures with a high degree of material rupture, such that the immediate post-collapse shape was difficult to identify. Figures 9(c) and 10(c) show typical short and long specimens after volume-control pressure testing; these cylinders were nominally identical to those shown in Figs. 9 (b) and 10(b), respectively. Catastrophic failures were avoided while using the volume-control method, so that the final post-testing configurations were easily distinguishable. This was due to a combination of damping and stiffness associated with the internal specimen fluid, which slowed down and arrested the collapse event, respectively.

\section{Preservation of the Initial Collapse Mode}

The shape of certain specimens, up to and including the collapse load, has been shown by the strain gauge data to be a more-or-less regular sinusoidal pattern in the circumferential direction, while the deformations in the postcollapse region were dominated by a single lobe of this collapse shape. For example, Fig. 13 shows the distribution of circumferential strain in the unstiffened cylinder just before collapse and again after collapse had occurred and the specimen was completely unloaded. At collapse, the strain gauges indicate that the specimen has been deformed into roughly four circumferential waves, while the final configuration after unloading indicates that a single lobe of the collapse mode has dominated the post-collapse behaviour. This was confirmed by inspection of the cylinder after it was removed from the pressure chamber.

Figure 11(b) shows the unstiffened cylinder after it was tested to collapse and removed from the pressure chamber, and then loaded in the pressure chamber a second time to determine its "residual strength". The residual strength test resulted in significant permanent deformation, with the formation of three circumferential lobes. This will be discussed further in Section "SnapThrough Shell Buckling".

While control of the post-collapse deformations has been significantly improved with respect to a conventional airbacked pressure testing method, the preservation of the initial collapse mode in the cylinder specimens after volume-control testing was not always possible, even when the testing was stopped immediately after the occurrence of collapse. This is a consequence of using the volume-control method of testing, which regulates the generalized displacement, and represents a test rig with finite stiffness, i.e.
Fig. 13 Circumferential distribution of circumferential strain outside the shell at mid-length in the unstiffened cylinder

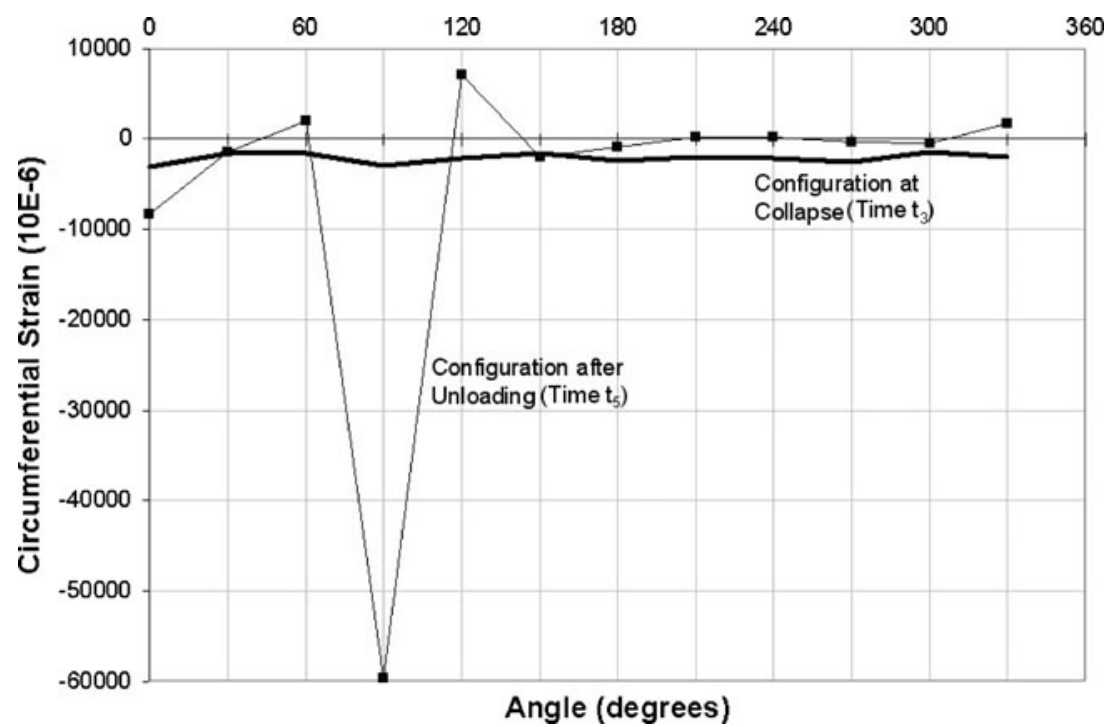


the finite stiffness of the testing fluid in the specimen. This emphasizes the importance of tracking pre- and postcollapse deformations with strain gauges in order to fully understand the collapse behaviour of the specimens and to make authentic comparisons between experimental and numerical results.

Of course, evidence of a purely elastic instability event would not be shown by the final specimen configuration after testing, since the specimen would be returned to its original shape after the load was removed. In the case of the unstiffened cylinder, collapse occurred while the material, at least at strain gauge locations, was still in the elastic range. The volume-control system allowed the buckling deformations to be controlled to such an extent that the strains could be traced and the collapse mode determined; however, the violence of the buckling event was not mitigated to the degree that permanent deformations were avoided.

\section{Control of Specimen Deformation Near the Critical Load}

Figure 14 shows partial load histories for the short and long cylinders tested using the volume-control method; system pre- and de-pressurization stages are not shown, and only the net pressures are plotted for the loading and unloading stages. Times corresponding to milestones in the testing procedure (see Table 3) are indicated for each test. The "kink" in the load history for the long cylinder at approximately $240 \mathrm{~s}$ is due to an adjustment that was made to the fluid-release valve to increase the flow (and loading) rate.

For the short cylinder, the formation of the initial buckling lobe is indicated in the net pressure history by a slight drop in pressure at $t_{3}$. The cylinder was loaded slightly into the post-collapse region $\left(t_{3}-t_{4}\right)$, and then unloaded $\left(t_{4}-t_{5}\right)$ by opening the cross-over valve. Figure 9 (c) shows the short cylinder after it was loaded a second time (i.e. to determine its residual strength), well into the post-collapse region, resulting in the formation of several lobes in a classical interframe buckling pattern.

During collapse, the rapidly decreasing shell volume due to inward buckling encounters resistance from the pressurized fluid inside the specimen. If the testing fluid were infinitely stiff, this would represent a limit point in the generalized displacement. Inward buckling results in a sharp increase in the internal specimen pressure, and corresponding decrease in net pressure.

Tests undertaken with a conventional air-backed setup provided very little information after the peak collapse load was reached, as the rapid and catastrophic buckling event caused the strain gauges and lead wires to be torn from the cylinders. Using the volume-control method, it was possible to trace the specimen behaviour during and after collapse. Strain gauges located about the circumference of the short cylinder indicated that initial collapse (at time $t_{3}$ in Fig. 14) resulted in a proportionally greater increase in shell strains compared to stiffener strains (Fig. 15). The largest shell strains were concentrated in one or two adjacent locations, indicating a small, localized buckle in the shell. These features are characteristic of interframe collapse. The strain data also indicate that the initial buckling mode was amplified in the post-collapse region, and resulted in permanent deformation that was observable after the test was completed. Since the buckling mode for the short cylinder was a small, localized lobe or dimple, the corresponding reduction in specimen volume was negligible.

The load history in Fig. 14 shows that the drop in net pressure at collapse (at time $t_{3}$ ) was much greater for the
Fig. 14 Partial load history for short and long cylinders during volume-control testing

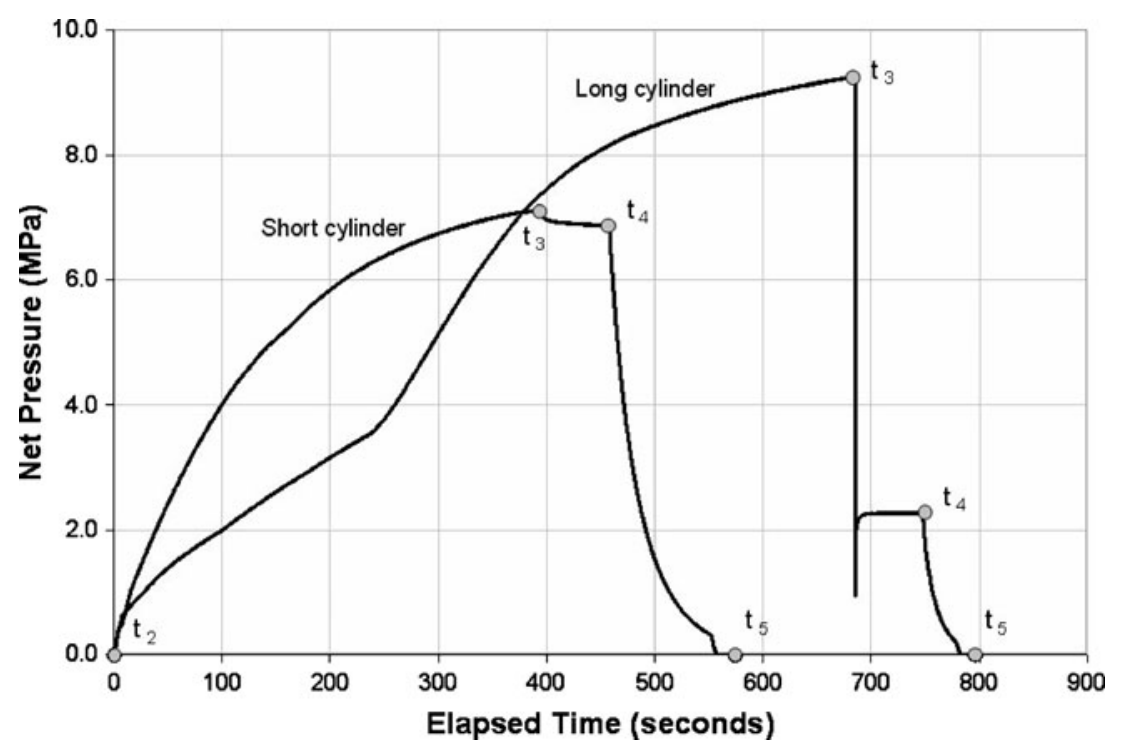


Fig. 15 Strain-pressure plots at location of initial collapse for short and long cylinders

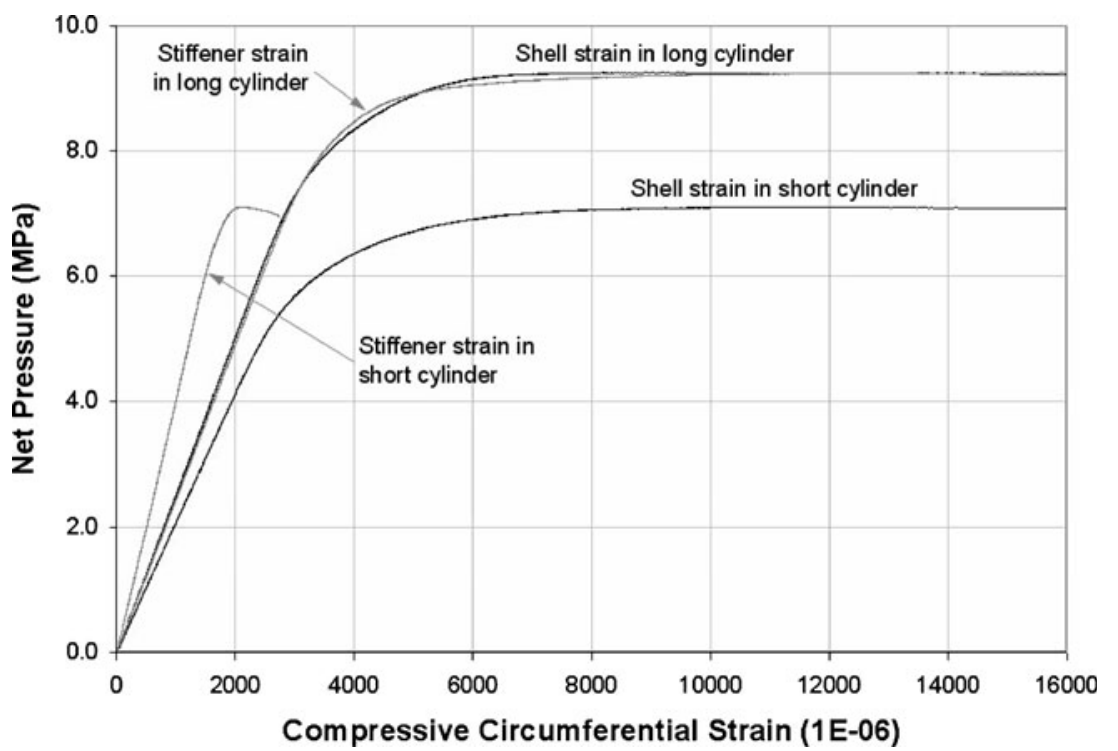

long cylinder. Circumferentially distributed strain gauges on the shell and ring-stiffeners indicate that cylinder failed in an overall mode, i.e. both shell and stiffener strains increased significantly at collapse (Fig. 15). This led to a more general loss of stiffness and a large buckling lobe concentrated around the simulated corrosion, as shown in Fig. 10(c). A similar large drop in applied pressure after collapse was observed for other specimens failing in an overall collapse mode [67].

Figure 16 shows the pressure-time history of the long cylinder at collapse, as well as the time-synchronized circumferential compressive strain at a central stiffener at the location of failure. This figure shows the sudden and rapid collapse mechanism, which occurs slightly after the incidence of the limit load. The dynamic nature of the buckling process is demonstrated by the high strain rate and the post-collapse oscillation of the pressure, and to a lesser

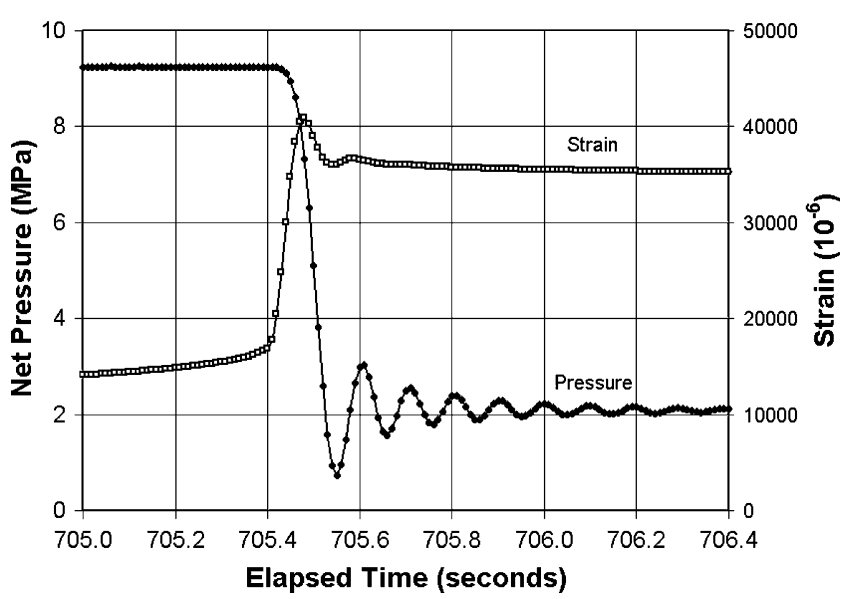

Fig. 16 Pressure and strain history for long cylinder at collapse $(100 \mathrm{~Hz}$ sampling rate) extent, strain. The interaction between the structure and the fluid causes damping of the structure, as shown by the immediate attenuation of the strain in Fig. 16, and generates pressure waves in the fluid that are more slowly attenuated.

The peak in the strain data of Fig. 16 occurs before the minimum pressure is reached, suggesting a load-reversal. Figure 17 shows the pressure-strain relationship for the long cylinder at the stiffener where collapse occurred. This figure shows that the behaviour of the cylinder is as expected immediately after collapse begins; that is, a rapid growth in strain with some loss of net pressure. However, after the initial stage of collapse, the strain begins to decrease with a corresponding drop in net pressure, which is what would be expected if the cylinder was being unloaded. This eventually leads to a period of strain and pressure oscillation as shown in Fig. 16.

The preceding phenomena occur while the volumecontrol system was set in the loading configuration $\left(t_{3}-t_{4}\right.$ in Table 3); that is, fluid was still being released from the specimen. What appears to be unintentional unloading, which was only observed for long cylinders failing with large buckling lobes, is due to an increase in the internal pressure of the specimen due to the rapidly decreasing shell stiffness and, consequently, volume, at collapse. This arises due to the stiffness of the internal specimen fluid, and is a necessary outcome of arresting the collapse event before the specimen is completely ruptured. The volume-control system can slow down and arrest buckling, but it cannot completely control the buckling event, so that the resulting pressure-strain relationship in the post-collapse region is influenced by dynamic effects. This must be taken into consideration when studying the post-collapse behaviour of the specimen and when making comparisons between experiments and numerical results. 
Fig. 17 Pressure-strain relationship at the stiffener of the long cylinder

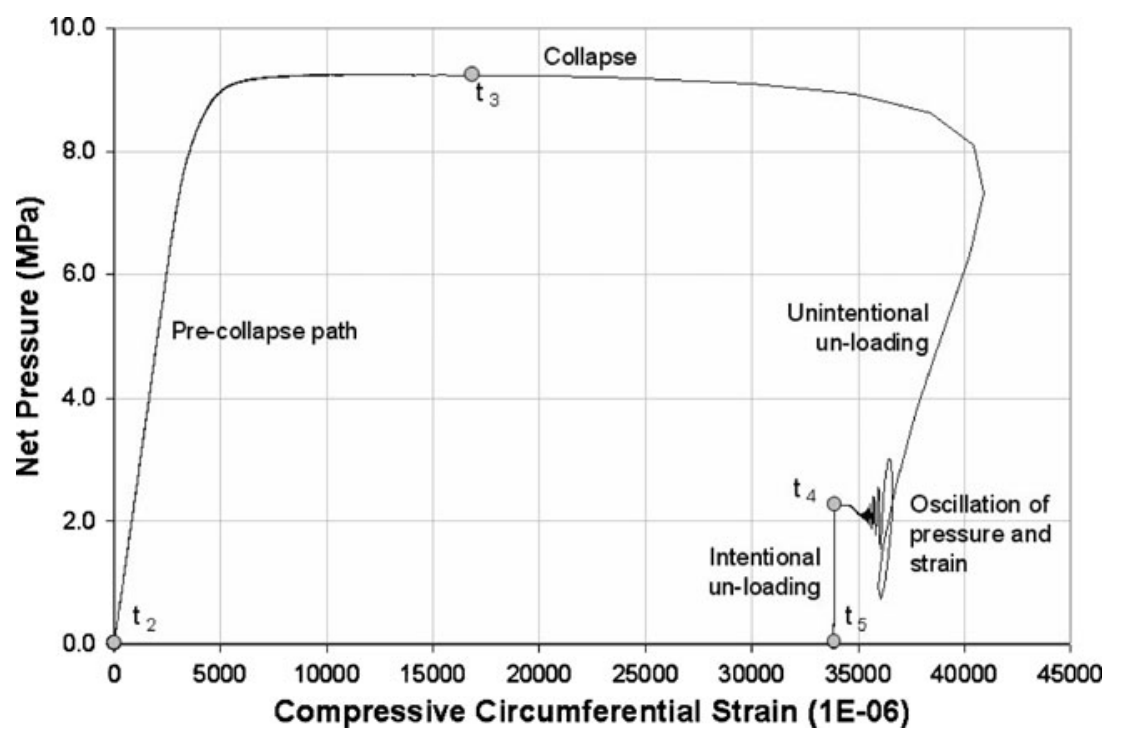

Snap-Through Shell Buckling

Figure 18 shows the strain-pressure relationship for the residual strength test of the unstiffened cylinder, i.e. the second pressure test after the cylinder was first loaded to collapse and unloaded completely. This figure shows the results for a circumferentially-oriented strain gauge located at an outward buckling lobe, with respect to the final configuration shown in Fig. 11(b). This location was chosen because the local strain increases more-or-less monotonically for a large portion of the testing regime, resulting in a clear strain-pressure plot.

The evolution of the deformed shape of the cylinder is shown in Fig. 18 by plotting the measured circumferential strains in the shell at mid-length at various stages of loading. The specimen began the residual strength test in the configuration indicated by the circumferential strain distribution after initial testing (Fig. 13); that is, having a single dominant imperfection lobe. This shape was preserved in the initial stages of the residual strength test, i.e. up to the first limit point in the load, at point A in Fig. 18. A second buckling lobe began to form as the load recovered, reaching a second limit point in the load at B, after which the load began to drop. The second buckling lobe is clearly indicated by the circumferential strain distribution at the local load minima at point C. Additional limit points in the load are shown in Fig. 18 as the test progresses, with the final configuration of three unevenly distributed buckling lobes at point $\mathrm{F}$ matching the observed post-testing shape of the specimen, as shown in Fig. 11(b).

Figure 18 suggests that the several maxima and minima in the pressure-strain history are mainly due to the formation of additional buckling lobes (snap-through), which is evidence of the generalized displacement-control
Fig. 18 Residual strength test of the unstiffened specimen, showing the strain-pressure curve for a single strain gauge throughout the loading history (solid line) and the circumferential strain distribution in the shell at selected points on the curve

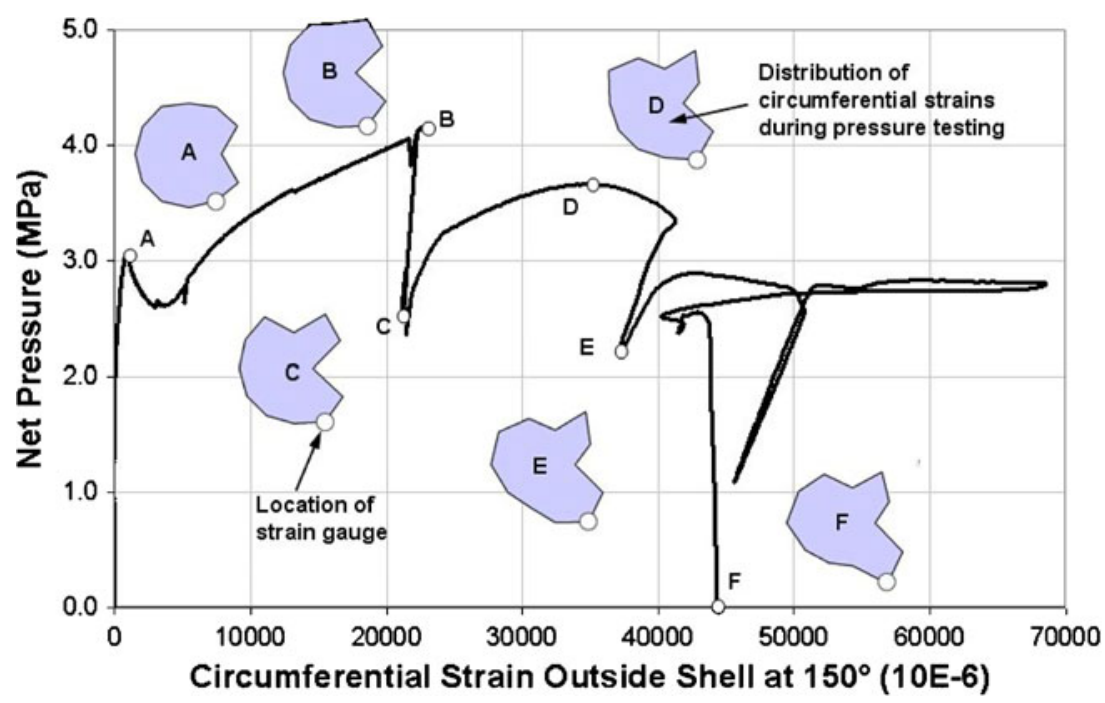


nature of the testing apparatus. Figure 18 also shows what appears to be the occurrence of "snap-back" behaviour, whereby the deformation (strain in this case) and load are simultaneously reduced while the test is progressing along the equilibrium path (e.g. between point $B$ and point $C$ ). This figure shows the strain at a single location, so that the generalized strain (i.e. displacement) may not indicate snapback. Furthermore, these strain-reversals may be due to load reversal caused by the decrease in specimen volume due to the formation of the buckling lobes, as discussed above.

\section{Relative Displacement of Experimental Apparatus}

The experimental studies discussed above indicate that the volume-control system provided better control of the specimen displacements, especially near the critical load, than a conventional air-backed system. This section will use the expressions for relative displacement $\left(\Delta u_{2} / \Delta u_{1}\right)$ derived in Section "Control of Specimen Deformation Using Various Pressure Testing Methods" to determine if they predict a similar outcome, and to judge if another option, e.g. a conventional fluid-backed system, would have provided even better results.

The various stiffness and volume parameters for the pressure testing apparatus used in the experiments described in this paper are listed in Table 4. The specimen stiffness in Table 4 is for the unstiffened cylinder, and was approximated as the change in volume of the specimen under a uniform external pressure, as predicted using a linear static finite element analysis with general shell elements. The equivalent stiffness shown in equation (1) was used to evaluate the fluid stiffnesses listed in Table 4.

Table 5 lists the relative displacement for the various pressure testing systems, determined using equations (6) through (8). These values indicate that the relative displacement for the conventional air-backed system used in the experiments was two orders of magnitude less than the relative displacement for the volume-control system used in later experiments. This would suggest a greater degree of specimen control for the volume-control system in the pre-buckling range. The relative displacement for a conventional fluid-backed system, although one was not used in these experiments, is also listed in Table 5. As expected from the study of relative displacement in Section "Control of Specimen Deformation Using Various Pressure Testing Methods", this value indicates that specimen control for this type of system would be even worse than for the air-backed system. The large discrepancy in relative displacement between the conventional and volume-control systems is due to the significantly greater stiffness of the specimen fluid and/or specimen compared to the chamber fluid, i.e. due to the relatively large pressure chamber.

The incremental specimen volume change at collapse due to a complete loss of load-carrying capability by the specimen, $\Delta u_{2}$, is also presented in Table 5 for each system. These values, calculated using equations (10) and (11), indicate that fluid-backed systems, whether conventional or volume-control, reduce the change in specimen volume at collapse by two orders of magnitude relative to an air-backed system. This, in combination with dynamic effects that play a role during buckling, explains the catastrophic failures observed for air-backed specimens.

Since the degree of specimen control for conventional pressure testing systems may be improved by decreasing the volume of testing fluid, a hypothetical smaller pressure chamber was studied. Stiffness parameters for the second pressure chamber (Table 4) are identical to the actual pressure testing rig, except that the volume of the pressure chamber is reduced so that the clearance around the test specimen is much smaller-approximately $10 \%$ of the maximum specimen radius. This increases the stiffness of the pressure chamber fluid to such an extent that the relative displacements for the conventional systems are dramatically improved with respect to the actual apparatus, and even somewhat better than the volume-control system (see Table 5). The fluid-backed systems are still better at arresting the collapse displacements $\left(\Delta u_{2}\right)$, but the degree of improvement over the air-backed systems is less than an order of magnitude.

\section{Conclusions and Recommendations}

Conventional pressure testing systems were reviewed and expressions developed to estimate the degree of specimen
Table 4 Stiffness parameters for experimental pressure testing systems

\begin{tabular}{lll}
\hline Parameter & Actual experimental apparatus & Hypothetical experimental apparatus \\
\hline$B_{c f}, B_{s f}$ (mineral oil) & $1620 \mathrm{MPa}$ & $1620 \mathrm{MPa}$ \\
$V_{0, c f}$ & $1.583^{\mathrm{E}}+09 \mathrm{~mm}^{3}$ & $1.341^{\mathrm{E}}+07 \mathrm{~mm}^{3}$ \\
$V_{0, s f}$ & $1.716^{\mathrm{E}}+07 \mathrm{~mm}^{3}$ & $1.716^{\mathrm{E}}+07 \mathrm{~mm}^{3}$ \\
$k_{c f}{ }^{*}$ & $1.023^{\mathrm{E}}-06 \mathrm{~N} / \mathrm{mm}^{5}$ & $1.208^{\mathrm{E}}-04 \mathrm{~N} / \mathrm{mm}^{5}$ \\
$k_{s f}{ }^{*}$ & $9.441^{\mathrm{E}}-05 \mathrm{~N} / \mathrm{mm}^{5}$ & $9.441^{\mathrm{E}}-05 \mathrm{~N} / \mathrm{mm}^{5}$ \\
$k_{s}{ }^{*}$ & $1.143^{\mathrm{E}}-04 \mathrm{~N} / \mathrm{mm}^{5}$ & $1.143^{\mathrm{E}}-04 \mathrm{~N} / \mathrm{mm}^{5}$ \\
\hline
\end{tabular}


Table 5 Relative displacement parameters for experimental pressure testing systems

\begin{tabular}{lll}
\hline Pressure testing system & Pre-buckling relative displacement $\left(\Delta u_{2} / \Delta u_{1}\right)$ & Specimen displacement during buckling $\left(\Delta u_{2}\right)$ \\
\hline Actual experimental apparatus & & \\
Conventional air-backed & $8.872 \mathrm{E}-03$ & $7.819 \mathrm{E}+06 \mathrm{~mm}^{3}$ \\
Conventional fluid-backed & $4.878 \mathrm{E}-03$ & $8.383 \mathrm{E}+04 \mathrm{~mm}^{3}$ \\
Volume-control & $4.501 \mathrm{E}-01$ & $8.383 \mathrm{E}+04 \mathrm{~mm}^{3}$ \\
Hypothetical apparatus & & \\
Conventional air-backed & $5.138 \mathrm{E}-01$ & $6.624 \mathrm{E}+04 \mathrm{~mm}^{3}$ \\
Conventional fluid-backed & $3.665 \mathrm{E}-01$ & $3.718 \mathrm{E}+04 \mathrm{~mm}^{3}$ \\
Volume-control & $2.865 \mathrm{E}-01$ & $3.718 \mathrm{E}+04 \mathrm{~mm}^{3}$ \\
\hline
\end{tabular}

control available for these systems. A volume-control pressure testing apparatus was developed and implemented successfully in a shell buckling testing program. This system allowed the amount of testing fluid leaving the specimen, and thus the shell deformation, to be controlled up to, and slightly beyond, the limit load of the cylinder. Precise control of the shell deformation and applied load in the dynamic post-collapse region was not achieved for specimens that formed large buckling lobes compared to the specimen volume. This has been attributed to the sudden loss of stiffness, and subsequent decrease in specimen volume, due to inward buckling, and is thought to be a necessary consequence of arresting the collapse process before the shell is ruptured.

The authors have used the proposed volume-control system to replace a conventional pressure testing setup used earlier in their testing program. The modified test apparatus eliminated the large, undesired post-collapse deformations and material rupture that occurred in the earlier testing. The post-collapse shape was preserved in all cases; however, this shape did not necessarily match the initial collapse mode at the peak load. As such, caution is required when interpreting the experimental results, and strain gauges were found to be invaluable for tracking the full load-deformation history of test specimens and identifying the mode of failure. Testing of the post-collapse strength of the cylinders was possible, with tracking of several load peaks and valleys in this region, which was not possible with a previously used conventional pressure testing setup.

The simple expressions for relative displacement and incremental specimen displacement during buckling developed in Section "Control of Specimen Deformation Using Various Pressure Testing Methods" have been shown to be at least qualitatively correct. They can be used to produce a rough estimate of the performance of a given pressure testing system, keeping in mind that as the value of relative displacement, $\left(\Delta u_{2} / \Delta u_{1}\right)$, approaches unity, the control of pre-buckling specimen displacements improves. The magnitude of buckling displacement, $\Delta u_{2}$, has been shown to be reduced by filling the specimen with the testing fluid.
In general, when planning experiments, it is recommended that a conventional fluid-backed pressure testing system be used when the pressure chamber is only slightly larger than the test specimens. A fluid-backed system with an outlet may be the best option for this situation, as it offers the better pre-buckling specimen control associated with an air-backed system, as well as at least some of the damping characteristics of a closed fluid-backed system. An air-backed system with an open-ended pressure chamber has the advantage of access to the interior of the specimen for instrumentation and observation during testing. This setup may be a good option if catastrophic specimen failures can be avoided by minimizing the volume of testing fluid in the chamber.

When the specimen is much smaller than the pressure chamber, as was the case in the experiments described in this paper, it is recommended that a volume-control system be used if control over the specimen pre-buckling deformation is important. The volume-control system has the additional benefits that the pump is not running during the loading stages and that the specimen displacements are controlled using needle valves rather than turning the pump on and off. These considerations may influence the choice of pressure testing system when the relative displacements are similar for all types of pressure testing, e.g. the hypothetical apparatus in Table 4. Kinra's system [56] behaves similarly to the volume-control system, and is simpler to implement; but since the specimen is loaded during the pre-pressurization stage in Kinra's method, its advantages must be weighed against the risk of premature specimen collapse or yielding during pre-pressurization so that the actual collapse load cannot be determined.

For any existing pressure testing apparatus, greater control of the specimen deformation can be achieved by decreasing the volume of the chamber fluid and specimen fluid (or by increasing its bulk modulus) for conventional and volume-control systems, respectively. This volume reduction could be achieved by, for example, using a stiff steel insert in the pressure chamber or specimen, although this may interfere with instrumentation and wiring. Besides 
improving the control of specimen deformation, reducing the volume of testing fluid has a universal benefit, in that less strain energy is stored up in the testing system to be released at collapse. This helps to mitigate catastrophic specimen failures and allows better tracking of the postcollapse behaviour.

Acknowledgements The experimental work described in this paper was jointly funded by the Netherlands Ministry of Defence and the Department of National Defence of Canada, and copyright remains with the Governments of those countries. The authors would like to thank their many colleagues in the Netherlands and Canada who have contributed to the experimental program.

Open Access This article is distributed under the terms of the Creative Commons Attribution Noncommercial License which permits any noncommercial use, distribution, and reproduction in any medium, provided the original author(s) and source are credited.

\section{References}

1. BSI (1980) BS 5500 British standard specification for unfired fusion welded pressure vessels, Issue 5, United Kingdom: British Standards Institution (BSI)

2. ECCS (1988). Buckling of steel shells: European recommendations, Brussels: European Convention for Constructional Steelwork (ECCS)

3. DPA (2001). SSP 74 Design of submarine structures. United Kingdom: defence procurement agency, Sea Technology Group

4. Sze KY, Liu XH, Lo SH (2004) Popular benchmark problems geometric nonlinear analysis of shells. Finite Elem Anal Des 40:1551-1569

5. Clarke MJ, Hancock GJ (1990) A study of incremental-iterative strategies for non-linear analyses. Int J Numer Methods Eng 29:1365-1391

6. Riks E (1979) An incremental approach to the solution of snapping and buckling problems. Int J Solids Struct 15:529551

7. Crisfield MA (1981) A fast incremental/iterative solution procedure that handles "snap-through". Comput Struct 13:55-62

8. Crisfield MA (1991) Nonlinear finite element analysis of solids and structures. Wiley \& Sons, Toronto

9. Weingarten VI, Seide P (1965) Elastic stability of thin-walled cylindrical and conical shells under combined external pressure and axial compression. AIAA J 3(5):913-920

10. Wang LR-L (1968) Boundary disturbance and pressure rate on the buckling of spherical caps. AIAA J 6(11):2192-2193

11. Singer J, Bendavid D (1968) Buckling of electroformed conical shells under hydrostatic pressure. AIAA J 6(12):2332-2338

12. Schneider MH, Snell RF, Tracy JJ, Power DR (1991) Buckling and vibration of externally pressurized conical shells with continuous and discontinuous rings. AIAA J 29 (9): 1515-1522

13. Guggenberger W (1995) Buckling and postbuckling of imperfect cylindrical shells under external pressure. Thin-Walled Struct 23:351-366

14. Aghajari S, Abedi K, Showkati H (2006) Buckling and postbuckling behaviour of thin-walled cylindrical steel shells with varying thickness subjected to uniform external pressure. ThinWalled Struct 44:904-909
15. Singer J, Arbocz J, Weller T (1998) Buckling experiments: experimental methods in buckling of thin-walled structuresVolume 1. Wiley \& Sons, New York

16. Singer J, Arbocz J, Weller T (2002) Buckling experiments: experimental methods in buckling of thin-walled structuresVolume 2. Wiley \& Sons, New York

17. Sandor BI (1998) Mechanics of materials. In: Kreith F (ed) The CRC handbook of mechanical engineering. CRC Press, Boston

18. Southwell RV (1932) On the analysis of experimental observations in problems of elastic stability. Proceedings of the Royal Society, London, Series A 135:601-616

19. MacKay JR (2007) Experimental investigation of the strength of damaged pressure hulls-Phase 1. Defence Research and Development Canada-Atlantic, Technical Memorandum 2006-304

20. Slankard RC, Nash WA (1953) Tests of the elastic stability of a ring-stiffened cylindrical shell, model BR-5 $(\lambda=1.705)$ subjected to hydrostatic pressure. David Taylor Model Basin, Report 822

21. Wenk E Jr, Slankard RC, Nash WA (1954) Experimental analysis of the buckling of cylindrical shells subjected to external hydrostatic pressure. Exp Stress Anal 12(1):163-180

22. Slankard RC (1955). Tests of the elastic stability of a ringstiffened cylindrical shell, model BR-4 $(\lambda=1.103)$, subjected to hydrostatic pressure. David Taylor Model Basin, Report 876

23. Galletly GD, Slankard RC, Wenk E Jr (1958) General instability of ring-stiffened cylindrical shells subject to external hydrostatic pressure-A comparison of theory and experiment. J Appl Mech 25:259-266

24. Schroeder FJ, Kusterer ET (1963) An experimental determination of the stability of conical shells. J Appl Mech 144-6

25. Goudie NM (1971) Collapse tests of two full-scale OBERON class dome bulkheads. Naval Construction Research Establishment, Report L12/TG42/71

26. Ross CTF, Aylward WR, Boltwood DT (1971) General instability of ring-reinforced circular cylinders under external pressure. RINA Transactions 113:73-82

27. Seleim SS, Roorda J (1986) Buckling behaviour of ring-stiffened cylinders, experimental study. Thin-Walled Struct 4:203-222

28. Ross CTF, Johns T (1988) Buckling and vibration of ringstiffened cones under uniform external pressure. Thin-Walled Struct 6:321-342

29. Ross CTF, Johns T (1990) Vibration and buckling of a thin-walled dome under external water pressure. J Ship Res 34(2):142-148

30. Ross CTF, Haynes P, Seers A, Johns T (1995) Inelastic buckling of ring stiffened circular cylinders under uniform external pressure. Proc ASME, Conf on Structural Dynamics and Vibration, PD-Vol 70, 207, 215, Houston, Texas

31. Ross CTF, Popken D (1995) Buckling of tube-stiffened prolate domes under external water pressure. Thin-Walled Struct 22:159179

32. Boote D, Mascia D, Monti M, Rizzuto E, Tedeschi R (1997) Elastic instability of thin cylindrical shells: numerical and experimental investigation. Ocean Eng 24(2):133-160

33. Ross CTF (1997) Inelastic general instability of ring-stiffened circular cylinders and cones under uniform external pressure. Struct Eng Mech 5(2):193-207

34. Ross CTF, Johns T (1998) Plastic axisymmetric collapse of thinwalled circular cylinders and cones under uniform external pressure. Thin-Walled Struct 30(1-4):35-54

35. Ross CTF, Waterman GA (2000) Inelastic instability of circular corrugated cylinders under external hydrostatic pressure. Ocean Eng 27:331-343

36. Ross CTF, Little APF, Adeniyi KA (2005) Plastic buckling of ring-stiffened conical shells under external hydrostatic pressure. Ocean Eng 32:21-36

37. Fairbairn W (1858) On the resistance of tubes to collapse. Philos Trans R Soc 148:389-413 
38. Blumenberg WF (1965) The effect of intermediate heavy frames on the elastic general instability strength of ring-stiffened cylinders under external hydrostatic pressure. David Taylor Model Basin, Report 1844

39. Galletly GD, Aylward RW, Bushnell D (1974) An experimental and theoretical investigation of elastic and elastic-plastic asymmetric buckling of cylinder-cone combinations subjected to uniform external pressure. Ing-Arch 43:345-358

40. Aylward RW, Galletly GD, Moffat DG (1975) Buckling under external pressure of cylinders with toriconical or pierced torispherical ends: a comparison of experiment with theory. J Mech Eng Sci 17(1):11-18

41. Creswell DJ (1978) Experimental determination of the elastic collapse pressures of some miniature aluminium stiffened cylinders. Admiralty Marine Technology Establishment, Report R78643B

42. Pegg NG (1989) Experimental determination of interframe buckling of a ring stiffened cylinder. Defence Research Establishment Atlantic, Technical Memorandum 89/209

43. Bosman TN, Pegg NG, Keuning PJ (1993) Experimental and Numerical Determination of the Nonlinear Overall Collapse of Imperfect Pressure Hull Compartments. In: Proceedings of Warship '93, International Symposium on Naval Submarines 4. Royal Institution of Naval Architects

44. Ross CTF, Humphries M (1993) The buckling of corrugated circular cylinders under uniform external pressure. Thin-Walled Struct 17:259-271

45. Ross CTF, Palmer A (1993) General instability of swedgestiffened circular cylinders under uniform external pressure. J Ship Res 37(1):77-85

46. Ross CTF, Sadler JR (2000) Inelastic shell instability of thinwalled circular cylinders under external pressure. Ocean Eng 27:765-774

47. Oliveira Jr SC, Pasqualino IP, Netto TA (2006) Experimental analysis of metal-composite pipes under external pressure. In: 25th International conference on offshore mechanics and arctic engineering. Hamburg: American Society of Mechanical Engineers, paper no. OMAE2006-92485

48. Liessem A, Marewski U, Groß-Weege J, Knauf G (2006) Methods for collapse pressure prediction of UOE linepipe. In: 25th International conference on offshore mechanics and arctic engineering. Hamburg: American Society of Mechanical Engineers, paper no. OMAE2006-92147

49. Ross CTF, Little APF, Brown G, Nagappan A (2008) Inelastic shell instability of geometrically imperfect aluminum alloy circular cylinders under uniform external pressure. Mar Technol 45(3):175-181

50. Boichot L, Reynolds TE (1965) Inelastic buckling tests of ringstiffened cylinders under hydrostatic pressure. David Taylor Model Basin, Report 1992

51. Khan R, Akanda S, Uddin W (1998) A new approach for instability testing of shells. Int J Press Vessels Piping 75:75-80

52. Blachut J (2002) Buckling of externally pressurized barrelled shells: a comparison of experiment and theory. Int J Press Vessels Piping 79:507-517
53. Blachut J (2003) Collapse tests on externally pressurized toroids. J Press Vessel Technol 125:91-96

54. New JC (1953) A nondestructive differential-pressure test for thin shells. J Appl Mech 75:48-52

55. Blumenberg WF, Reynolds TE (1955) Elastic general instability of ring-stiffened cylinders with intermediate heavy frames under external hydrostatic pressure. David Taylor Model Basin, Report 1588

56. Kinra RK (1978) Hydrostatic and axial collapse tests of stiffened cylinders. J Pet Technol 30:668-680

57. Midgley WR, Johnson AE Jr (1973) Experimental buckling of internal integral ring-stiffened cylinders. Exp Mech 13:145-153

58. Walker AC, Segal Y, McCall S (1982) The buckling of thinwalled ring stiffened steel shells. In: Ramm E (ed) Buckling of shells. Springer, New York, pp 275-304

59. Harding JE, Dowling PJ, Walker AC (1983) The buckling design of stringer stiffened shells subjected to combined pressure and axial compression. Proceedings-15th Annual Offshore Technology Conference 1983, Texas, 267-76

60. Miller CD, Grove RB (1983) Current research related to buckling of shells for offshore structures. Proceedings-15th Annual Offshore Technology Conference 1983, Texas, 277-83

61. Tsang SK, Harding JE, Walker AC, Andronicou A (1983) Buckling of ring stiffened cylinders subjected to combined pressure and axial compressive loading. In: Pressure Vessels and Piping Conference, Portland, American Society of Mechanical Engineers

62. Walker AC, McCall S (1987) Strength of damaged ring and orthogonally stiffened shells-Part I: plain ring stiffened shells. Thin-Walled Struct 5:425-453

63. Giezen JJ, Babcock CD, Singer J (1991) Plastic buckling of cylindrical shells under biaxial loading. Exp Mech 31(4):337-343

64. Frieze PA (1994) The experimental response of flat-bar stiffeners in cylinders under external pressure. Mar Struct 7:213-230

65. Miller CD, Vojta JF (1984) Strength of stiffened cylinders subjected to combinations of axial compression and external pressure. In: Proceedings of the Annual Technical SessionStructural Stability Research Council: Stability and Seismic Loading

66. Galletly GD, Pemsing K (1985) Interactive buckling tests on cylindrical shells subjected to axial compression and external pressure-A comparison of experiment, theory and various codes. Proc Inst Mech Eng 199(C4):259-280

67. MacKay JR (2007) Experimental investigation of the strength of damaged pressure hulls-Phase 2, Summary of experimental results. Defence Research and Development Canada-Atlantic, Technical Memorandum 2007-013

68. Kendrick S (1970) Externally pressurized vessels. In: Gill SS (ed) The stress analysis of pressure vessels and pressure vessel components. Pergamon, Toronto, pp 405-511

69. Jiang L, MacKay JR, Wallace J, Smith MJ, Norwood M, Bosman TN (2008) Finite Element Modeling of Collapse Experiments of Ring Stiffened Cylinders with Simulated Corrosion Damage. In: Proceedings of Warship 2008: Naval Submarines 9 2008, Glasgow 